\title{
Structures in solid state and solution of dimethoxy curcuminoids: regioselective bromination and chlorination
}

\author{
Petra Galer, Amalija Golobič, Jože Koller, Berta Košmrlj and Boris Šket ${ }^{*}$
}

\begin{abstract}
Background: Several papers described the structure of curcumin and some other derivatives in solid and in solution. In the crystal structure of curcumin, the enol $\mathrm{H}$ atom is located symmetrically between both oxygen atoms of the enolone fragment with an $\mathrm{O}$.... distance of $2.455 \AA$, which is characteristic for symmetrical H-bonds. In the solution, the geometry of the enolone fragment is attributed to the inherent disorder of the local environment, which solvates one of the basic sites better than the other, stabilizing one tautomer over the other. In this paper, how the position of methoxy groups in dimethoxy curcuminoids influence the conformation of molecules and how the halogen atoms change it when they are bonded at a-position in keto-enol part of molecules is described.

Results: Six isomers of dimethoxy curcuminoids were prepared. Conformations in solid state, which were determined by $X$-ray single crystallography and ${ }^{1} \mathrm{H}$ MAS and ${ }^{13} \mathrm{C}$ CPMAS NMR measurements, depend on the position of methoxy groups in curcuminoid molecules. In solution, a fast equilibrium between both keto-enol forms exists. A theoretical calculation finding shows that the position of methoxy groups changes the energy of HOMO and LUMO. An efficient protocol for the highly regioselective bromination and chlorination leading to a-halogenated product has been developed. All a-halogenated compounds are present mainly in cis keto-enol form.

Conclusions: The structures in solid state of dimethoxy curcuminoids depend on the position of methoxy groups. The NMR data of crystalline solid samples of 3,4-diOCH 3 derivative, XRD measurements and X-ray structures lead us to the conclusion that polymorphism exists in solids. The same conclusion can be done for 3,5-diOCH${ }_{3}$ derivative. In solution, dimethoxy curcuminoids are present in the forms that can be described as the coexistence of two equivalent tautomers being in fast equilibrium. The position of methoxy groups has a small influence on the enolic hydrogen bond. Theoretical calculations show that the energy gap between HOMO and LUMO depend on the position of methoxy groups and are lower in solution. Chlorination and bromination on a-position of 1,3-diketone moiety do not change the preferential form being cis keto-enol as in parent compounds.
\end{abstract}

Keywords: Dimethoxy curcuminoids, X-ray structures, NMR experiments of solids, Theoretical investigations, Regioselectivity, Enols, Halogenation, a-halodiketones

\footnotetext{
* Correspondence: boris.sket@fkkt.uni-lj.si

Faculty of Chemistry and Chemical Technology, University of Ljubljana,

Aškerčeva 5, SI-1000, Ljubljana, Slovenia
} 


\section{Background}

The natural product curcumin (chemical name: 1,7-bis(3methoxy-4-hydroxyphenyl)-1,6-heptadiene-3,5-dione) has been recognized for its medical properties and is utilized for the treatment of many diseases because of its antiinflammatory, anti-oxidant, anti-viral, and anti-angiogenic properties [1-6]. Curcumin has demonstrated preventive activity against $\mathrm{A} \beta$ aggregation in Alzheimer' models $[7,8]$ and activity against various cancers [9-12] including leukaemia, liver, breast and prostate cancers.

Several papers described the structure of curcumin and some other derivatives in solid and solution. The crystal structure of curcumin was first determined in 1982 by Tønnesen et al. [13]. It was stated that the enolic $\mathrm{H}$ atom was statistically distributed over two oxygen atoms and each position having half occupancy. A redetermination of the crystal structure of curcumin was done by Row et al. in 2007 [14] using curcuminoid powder extracted from turmeric without further purification. They observed that the enol $\mathrm{H}$ atom is located symmetrically between both oxygen atoms of an enolone fragment with the $\mathrm{O} \cdots \mathrm{O}$ distance of $2.455 \AA$, which is characteristic for a symmetrical $\mathrm{H}$-bond. It is also known from the literature that substitution of a hydroxy group with an acetoxy group, also an electron donating, in the phenyl ring of curcumin changes the crystal structure. 4-Acetoxy derivative [15] of curcumin exists in the keto-enol form in which the enol $\mathrm{H}$-atom is disordered between both oxygen atoms. Authors also confirm the structure of the parent compound reported more than 20 years before by Tønnesen et al. in reference [13].

In 2011 Nangia and co-workers published the paper in which described that curcumin exists in three polymorphs and an amorphous phase. The molecule exists in the $\beta$ keto enol tautomer form in all crystal structures. In one polymorph the molecule has a slightly twisted conformation, but is linear, planar in other two polymorphs [16].

In the solution, the geometry of the enolone fragment is attributed to the inherent disorder of the local environment, which solvates one of the basic sites better than the other, stabilizing one tautomer over the other.

Curcumin is essentially in only cis keto-enol form in numerous solvents, ranging from chloroform to mixtures of DMSO and water with varying $\mathrm{pH}$ in the range 3-9 [17-24]. Theoretical calculations have established that the cis keto-enol form is about $7.75 \mathrm{kcal} \mathrm{mol}^{-1}$ more stable than the cis diketo form $[1,25]$. Three possible structures of curcumin [26] can exist: the $\beta$-diketone tautomer and two equivalent asymmetric keto-enol tautomers with strong intramolecular H-bonds (Scheme 1).

The presence of halogen atoms in many natural products profoundly influences their biological activity [27]. However, in the literature only a few reports about the direct introduction of halogen atom in curcumin or curcuminoid molecules have been found [28-31]. These molecules are a relatively complex conjugate system with several active sites. Most of the $\beta$-diketones and $\beta$-keto esters that have been chlorinated, brominated and iodinated by numerous reagents and methods [32,33] usually contain one active methylene group as the only reactive site for halogenations [34-36].

We have recently developed a convenient and efficient method to introduce a halogen atom regioselectively into a methylene group in 1,3-diketone moiety or to an activated phenyl ring of 1-phenyl-3-(3,5-dimethoxyphenyl)-propane-1,3-dione using $\mathrm{N}-\mathrm{X}$ reagents, such as NXS ( $N$-halo succinimide), NXSacc ( $N$-halo saccharin), and F-TEDA (1chloromethyl-4-fluoro-1,4-diazoniabicyclo[2,2,2]octane bis tetrafluoroborate) or NFTh (1-hydroxy-4-fluoro-1,4-diazoniabicyclo[2,2,2] octane bis tetrafluoroborate) in the presence of $\mathrm{LiClO}_{4}$ and $\mathrm{CH}_{3} \mathrm{CN}$ as solvent [37]. We determined that introduction of a halogen atom at $\alpha$-position in 1,3-dione moiety of 1-phenyl-3-(3,5-dimethoxyphenyl)propane-1,3-dione dramatically changes the conformation, being 1,3-diketone in comparison with the parent compound in which the favoured form is keto-enolic.

\section{Results and discussion}

As it is known that electron donating groups have a quite different effect in their being bonded at orto and para or meta position in the phenyl ring we determined how the

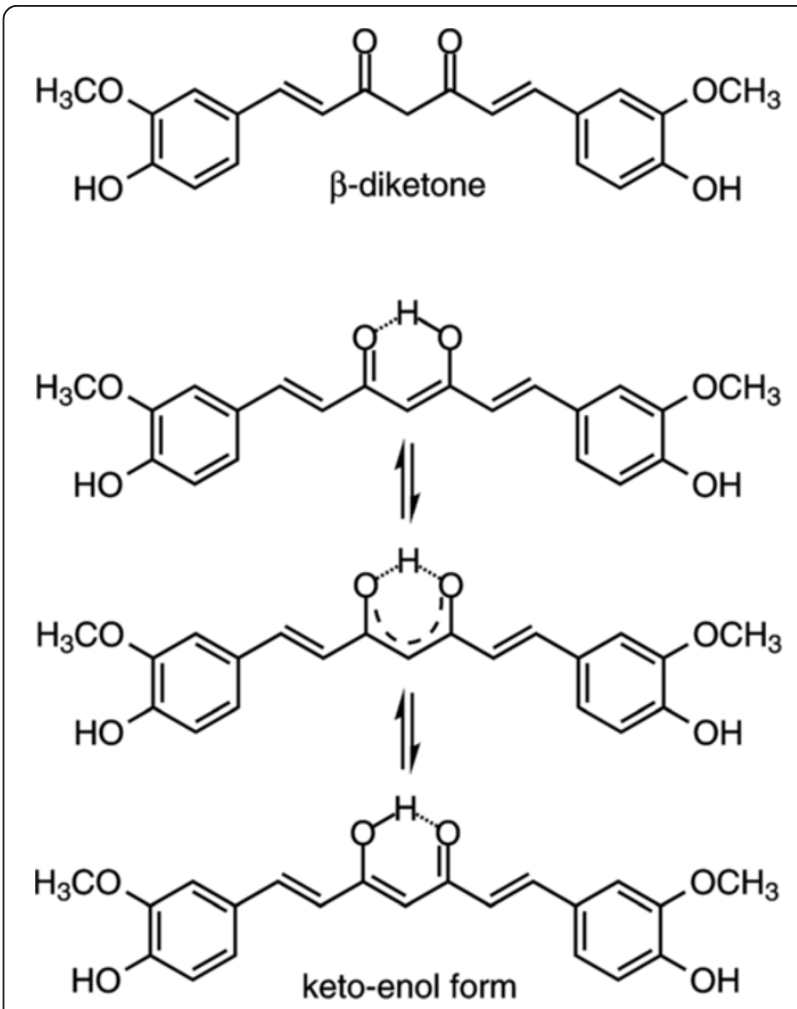

Scheme 1 Tautomeric forms of curcumin. 
position of the methoxy groups in dimethoxy substituted curcuminoids influence the preferent tautomer form in both a solid and in a solution. We chose dimethoxy curcuminoids also for the following reasons: they contain (a) an activated methylene group in 1,3-diketone moiety, (b) a highly activated phenyl ring with two methoxy groups and (c) a double $\mathrm{C}=\mathrm{C}$ bond in a conjugate position with the phenyl ring and 1,3-diketone moiety.

We also examined how the different positions of the methoxy groups is reflected in electron density distribution over the whole conjugate system and how the preferent tautomers in the solution influence the regioselectivity of halogenation. Is the activated phenyl ring or the activated methylene group the most reactive position?

\section{Synthesis of dimethoxy curcuminoids 2a-f}

To test the recently described protocol in the curcuminoid series, six isomers of dimethoxy derivatives were prepared using slightly modified literature procedures [30,38-42] (Figure 1). In all cases, a higher yield of curcuminoids were obtained and no additional purification by flash chromatography were necessary.

\section{Crystal structures of compound $2 \mathrm{~d}$ and $2 \mathrm{e}$}

The structures of dimethoxy curcuminoids in solid form were determined by X-ray crystallography. The ORTEP drawing of compound $\mathbf{2 d}$ showing the asymmetric unit, which contains one 2,6-dimethoxy curcuminoid molecule (Figure 2a) in cis keto-enol form. A difference Fourier map (Figure 2b) shows the two largest peaks corresponding to one $\mathrm{H}$ atom bonded to $\mathrm{O} 1 \mathrm{a}(\mathrm{O} 3)^{*}$ and one $\mathrm{H}$ atom bonded to $\mathrm{C} 1(\mathrm{C} 4)\left(\mathrm{sp}^{2}\right.$ hybridised) in plane of enolone moiety (O1a (O3), C2a (C3), C1 (C4), C2b (C5), and O1b (O5)). "In brackets and italicized, the numbering of atoms using in IUPAC nomenclature are given. There is no peak bonded to O1b (O5) that would indicate a disordered $\mathrm{H}$-atom of another keto-enol form. A possible explanation comes from the crystal packing in which the surrounding of O1a (O3) atom is different than of O1b (O5), (Figure 2c). C2a-O1a (C3-O3) Distance (1.294(2) $\AA$ ) is remarkably longer than C2b-O1b (C5-O5) (1.279(2) $\AA, \Delta / \sigma=7.5)$ and $C 1-C 2 \mathrm{a}(C 4-C 3)(1.380(3) \AA)$ is quite shorter than $\mathrm{C} 1-\mathrm{C} 2 \mathrm{~b}(\mathrm{C} 4-\mathrm{C} 5)(1.405(3) \AA, \Delta / \sigma=$ 13). In contrast, both lengths $\mathrm{C} 2 \mathrm{a}-\mathrm{O} 1 \mathrm{a}(\mathrm{C} 3-\mathrm{O} 3)$ and $\mathrm{C} 1-$ $\mathrm{C} 2 \mathrm{~b}(\mathrm{C} 4-\mathrm{C} 5)$ are remarkably shorter than the corresponding pure single bonds $(\mathrm{C}-\mathrm{O} \approx 1.37$ and $\mathrm{C}-\mathrm{C} \approx 1.48 \AA$ ) and the pairs of bonds $\mathrm{C} 2 \mathrm{~b}-\mathrm{O} 1 \mathrm{~b}(\mathrm{C} 5-\mathrm{O} 5)$ and $\mathrm{C} 1-\mathrm{C} 2 \mathrm{a}(\mathrm{C} 4-$ C3) are longer than the corresponding typical double bonds $(\mathrm{C}=\mathrm{O} \approx 1.20$ and $\mathrm{C}=\mathrm{C} \approx 1.33 \AA$ ). The donor of the intramolecular hydrogen bond is $\mathrm{O} 1 \mathrm{a}(\mathrm{O} 3)$ and the acceptor $\mathrm{O} 1 \mathrm{~b}$

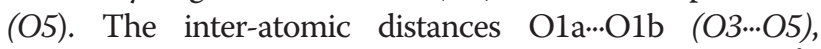

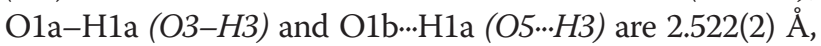

1.04(5) $\AA$ and 1.53(4) $\AA$, respectively. The O1a-H1a...O1b (O3-H3...O5) angle is $158(4)^{\circ}$.

$\pi$-Delocalization into enolone fragment was determined from $\pi$-delocalization index $\lambda_{Q}$ calculated with Equations 1, 2, 3 and 4, using the experimental determined bond distances [43]. $\lambda_{Q}=0.437$, showing that the degree of delocalization is approximately $87 \%$.

$$
\begin{aligned}
& q_{1}=d(C 3-O 3)-d(C 5-O 5) ; \\
& q_{2}=d(C 4-C 5)-d(C 4-C 3) \\
& Q=q_{1}+q_{2} \\
& \lambda=\lambda_{Q}=\left(1-Q / Q_{0}\right) / 2 \text { and } Q_{0}=0.320 \AA
\end{aligned}
$$

Percentage of delocalization:

$\operatorname{Del} \%=100(1-|2 \lambda-1|)$

The molecules deviate from planarity: the planes through dimethoxy aromatic rings are for 6.59(5) and $9.48(5)^{\circ}$ out of plane through the central, enolic part of molecules.

The crude product of $\mathbf{2} \mathbf{e}$ was further purified in two different ways. (a) To the crude product, EtOAc was added, insoluble material was filtered off, and the solvent was evaporated under reduced pressure. The oily product obtained was slowly crystallized. Under vigorous stirring methanol was added to eliminate the impurities. Dark red color crystals, from suspension, were filtered off (termed solid 1). (b) To the crude product water was added to eliminate the inorganic materials. After extraction with EtOAc and evaporation of the solvent under reduced pressure an orange colored solid was obtained (termed solid 2) (Figure 3). From both solids singlecrystals (polymorph 1 and 2) were obtained and X-ray structures were done.

The crystal structure of polymorph 1 consists of the symmetric 3,4-dimethoxy curcuminoid molecules (Figure 4a). One half of the molecule is related symmetrically to the other half by the twofold axis. A difference Fourier map of polymorph 1 (Figure 4b) clearly shows the two peaks in the plane of $\mathrm{O} 1$ (O3), $\mathrm{C} 2$ (C3), $\mathrm{C} 1$ (C4), $\mathrm{C} 2^{\mathrm{i}}(\mathrm{C} 5)$ and $\mathrm{O}^{\mathrm{i}}$ (O5) located on a twofold axis (i: $-\mathrm{x}, \mathrm{y},-\mathrm{z}+12)$ : one corresponding to $\mathrm{H}$ atom bonded to $\mathrm{C} 1$ (C4) ( $\mathrm{sp}^{2}$ hybridised), excluding the diketo form, and another one representing enol hydrogen atom centred between $\mathrm{O} 1$ (O3) and $\mathrm{O}^{\mathrm{i}}$ (O5) at the distance 1.358(18) $\AA$ from both of $\mathrm{O}$ atoms. Contrary to structure of $\mathbf{2 d}$ both $\mathrm{O}$ atoms $\left(\mathrm{O} 1\right.$ (O3) and $\mathrm{O} 1^{\mathrm{i}}$ (O5)) are due to the symmetry in the same crystal surrounding, see Figure 4c. Polymorph 1 forms a very

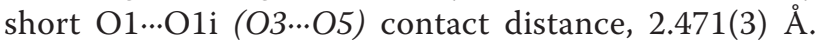
Appropriate pairs of bonds $\mathrm{C} 1-\mathrm{C} 2$ (C4-C3), $\mathrm{C} 1-\mathrm{C} 2 \mathrm{i}$ (C4-C5) and $\mathrm{C} 2-\mathrm{O} 1$ (C3-O3), $\mathrm{C} 2 \mathrm{i}-\mathrm{O} 1 \mathrm{i}(\mathrm{C} 5-\mathrm{O} 5)$ are identical in length, $1.397(3)$ and 1.290(3) $\AA$, respect-

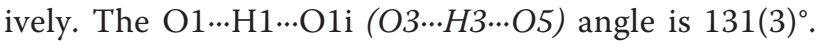


Such a symmetrical and delocalized structure of molecules was also obtained by checking with structure determination in space groups $P b c 2_{1}$ and $P 2_{1} c n$, when the whole molecule was taken as the asymmetric unit (Additional file 1: Figure S4).

Calculated parameter $Q=0 ; \lambda_{Q}=0.500$ (of polymorph 1) corresponding to the totally $\pi$-delocalized enolone fragment that is indicative of a symmetric single-well H-bond, typical of strong bond [44,45]. The molecules deviate from planarity: the dihedral angle between the plane through the dimethoxy aromatic ring and the plane through the central, enolic part of molecule is $18.33(9)^{\circ}$.

The ORTEP drawing of polymorph 2 showing the asymmetric unit, which contains two molecules, is presented in Figure 5a. A difference Fourier map (Figure $5 \mathrm{~b}$ ) of first molecule shows that an enolic $\mathrm{H}$ atom is bonded to O1d (O3), there is no peak bonded to O1c (O5). Distance C2d-O1d (C3-O3) 1.297(3) $\AA$ is longer than $\mathrm{C} 2 \mathrm{c}-\mathrm{O} 1 \mathrm{c}$ (C5-O5) 1.288(3) $\AA$ and $\mathrm{C} 1$ 2-C2d (C4-C3) 1.384(3) $\AA$ is shorter than C1-2-C2c (C4-C5) 1.396(3) A. Next, a difference Fourier map of second molecule from the asymmetric unit shows two maxima, approximately $1 \AA$ from O1b (O3) and O1a (O5) corresponding to two enolic $\mathrm{H}$ atoms with $50 \%$ occupancy. Contrary to the first molecule in the asymmetric unit, the distances $\mathrm{C} 2 \mathrm{~b}-\mathrm{O} 1 \mathrm{~b}$ (C3-O3) 1.286(3) $\AA$ and $\mathrm{C} 2 \mathrm{a}-\mathrm{O} 1 \mathrm{a}$ (C5-O5) 1.287(3) $\AA$ on one side and C1-1-C2b (C4-C3) 1.394(3) $\AA$ and C1-1C2a (C4-C5) 1.392(3) $\AA$ on the other side are nearly the same. A comparison between the above bond lengths in enolone moiety shows that the $\pi$-delocalization must be higher in second molecule than in the first. $\pi-$ Delocalization into enolone fragment was determined for both molecules in single crystal of polymorph 2. $\lambda_{Q}$ Index calculated from experimental determined bond distances is 0.467 for first molecule, corresponding to $93 \%$ of delocalization and 0.495 for second molecule showing that the degree of delocalization is $99 \%$.

Parameters of hydrogen-bonding geometry are collected in the table Figure 5. It is also important to emphasize the difference between polymorph 1 and polymorph 2 in orientation one of the substituted phenyl rings (see Figures 4 and 5). Comparing the experimental powder XRD pattern for solid 1 and 2 with those of calculated lines from the crystal structure of polymorph 1 and 2 clearly shows that solid 1 contains both polymorphs while solid 2 is pure polymorph 2 (Figure 3). To our surprise, experimental XRD pattern of solid 3, standing at room temperature for a long period of time, shows lines corresponding neither to polymorph 1 nor to polymorph 2 (Additional file 1: Figure S2).

\section{Solid-state NMR measurements of $2 \mathrm{~d}, \mathbf{2 e}$ and $\mathbf{2 f}$}

It is necessary to state that the $\mathrm{X}$-ray structure shows the picture of a single crystal and that the situation in the solid sample can be different if polymorphism exists. For this reason, ${ }^{1} \mathrm{H}$ MAS and ${ }^{13} \mathrm{C}$ CPMAS NMR experiments were carried out. In ${ }^{1} \mathrm{H}$ MAS NMR spectrum of 2,6- diOCH$_{3}$ derivative (2d), one signal for enolic proton appears at $15.99 \mathrm{ppm}$ and in ${ }^{13} \mathrm{C}$ CPMAS NMR spectrum; in addition to other signals, two signals at 186.9 and $182.1 \mathrm{ppm}$ corresponding to two different carbon atoms of the enolic part of molecule (Figure 6a). As the chemical shifts are very close to each other, the asymmetry of $\mathrm{H}$-bond in enolone moiety is not strongly expressed. The data obtained are in accordance with X-ray structure. 
(a)

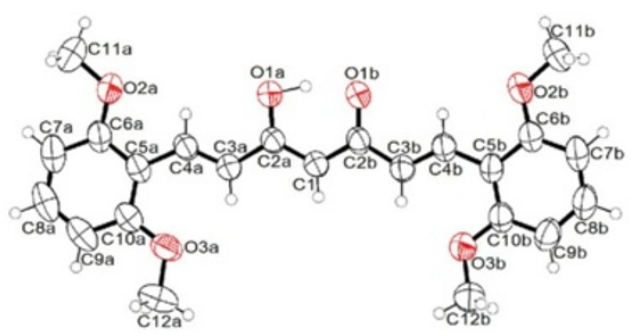

Hydrogen-bonding geometry $\left(A,{ }^{\circ}\right)$

\begin{tabular}{ccccc}
$\mathrm{D}-\mathrm{H} \cdots \mathrm{A}$ & $\mathrm{D} \cdots \mathrm{A}$ & $\mathrm{D}-\mathrm{H}$ & $\mathrm{H} \cdots \mathrm{A}$ & $\mathrm{D}-\mathrm{H} \cdots \mathrm{A}$ \\
\hline $\mathrm{O} 1 \mathrm{a}-\mathrm{H} 1 \mathrm{a} \cdots \mathrm{O} 1 \mathrm{~b}$ & $2.522(2)$ & $1.04(5)$ & $1.53(4)$ & $158(4)$
\end{tabular}

(b)

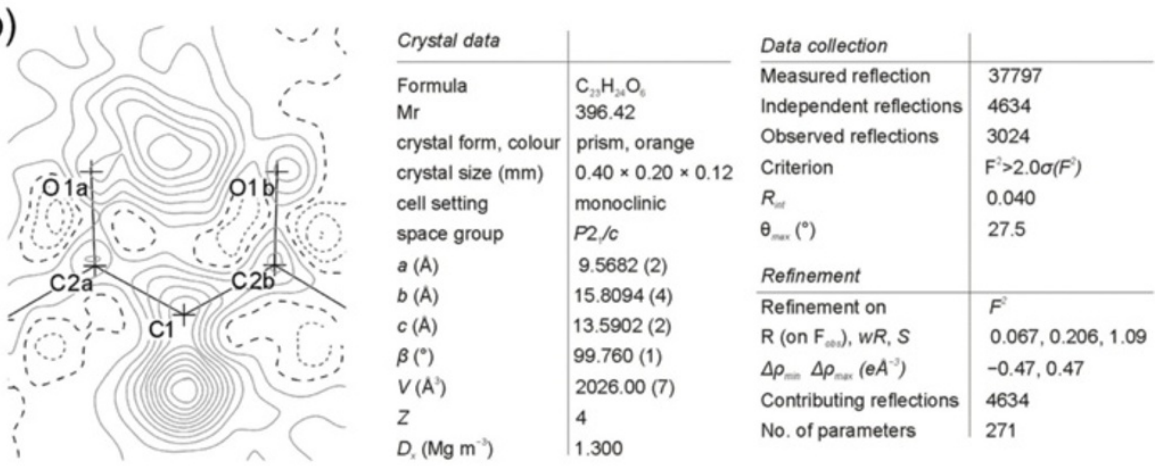

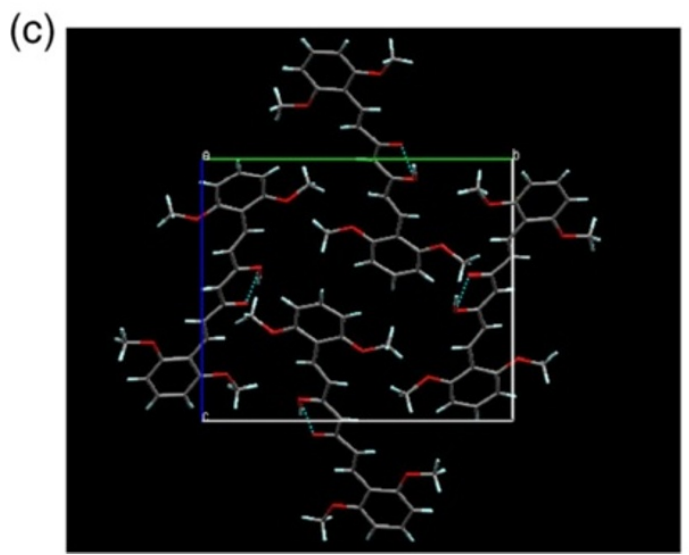

Figure $\mathbf{2}$ X-ray structure of $\mathbf{2 d}$. (a) ORTEP view of $2 \mathbf{d}$ (50\% probability displacement ellipsoids). Hydrogen atoms are drawn as circles of arbitrary radii. (b) Difference-Fourier map plotted in the mean plane of labelled atoms. Dotted contour lines indicate negative, dashed lines zero, and full lines positive residual electron density. (c) Packing of molecules of $2 d$ as viewed along a axis.

In the ${ }^{13} \mathrm{C}$ CPMAS NMR spectrum of 3,4- $\mathrm{diOCH}_{3}(\mathbf{2 e})$ (Figure $6 \mathrm{~b}$ ), the sample of crystalline solid 2 (orange, Figure 3), a structured overlapped signal appears between 180.0 and $185.0 \mathrm{ppm}$, corresponding to carbonyl carbon atoms of enolone moiety showing similar character and the fact is that an asymmetry in those parts of molecule are not strongly expressed. A relatively high degree of delocalization of both molecules confirm this conclusion. The data obtained are in accordance with the X-ray structure of polymorph 2 and the XRD pattern showing the presence of only one phase.

Solid 1 (dark red, Figure 3) contains two polymorphs, form 1 and form 2, and a small amount of an amorphous phase as determined from the XRD measurement. ${ }^{13} \mathrm{C}$ CPMAS NMR spectrum is rather complicated, with several signals in the region characteristic for carbonyl carbon atoms. By comparing ${ }^{13} \mathrm{C}$ CPMAS NMR spectra of solid 1 and solid 2 we are able to establish which signals probably belong to polymorph form 1 . At the beginning we were surprised to find such a complex spectrum, as we expected due to the symmetry in molecules of polymorph 1 only one signal for carbonyl carbon atoms of enolone moiety. From the X-ray analyses we have learned that the polymorph 1 is solvate, contains molecules of methanol which are disordered along the channels and therefore can randomly interact 
with the enolone part of the molecule and lead to different chemical shifts for carbonyl carbon atoms.

${ }^{1} \mathrm{H}$ MAS and ${ }^{13} \mathrm{C}$ CPMAS NMR spectra of 3,5- $\mathrm{diOCH}_{3}$ (2f) (Figure 6c) indicate that two different tautomers are present in the solid sample. On the basis of ${ }^{1} \mathrm{H}_{-}{ }^{13} \mathrm{C} 2 \mathrm{D}$ HETCOR spectrum we determined that one tautomer with an enolic proton at $16.39 \mathrm{ppm}$ correlates to ${ }^{13} \mathrm{C}$ CPMAS NMR spectrum with two signals at $\delta=178.8$ and $189.8 \mathrm{ppm}$ belonging to the carbon atom of the enolone part of the molecule. Relatively great differences in chemical shifts indicates a different character of both carbonyl atoms. A signal at higher chemical shifts (189.8 ppm) belongs to an atom of the carbonyl group while the signal at a lower chemical shift (178.8 ppm) belongs to an enolic carbon atom.

In the second tautomer (in ${ }^{1} \mathrm{H}$ MAS NMR spectrum two signals for enolic protons are present) signals at 182.5 and $180.4 \mathrm{ppm}$ correlate with the enolic proton signal at $13.85 \mathrm{ppm}$. A smaller difference between signals for both carbon atoms of the enolone part of the molecule reflects its similar character probably due to the higher symmetry in the enolone part of molecule.

\section{Structures of compounds 2 in solution}

The preferred structures of dimethoxy curcuminoids in solution were examined by ${ }^{1} \mathrm{H},{ }^{13} \mathrm{C}$ NMR (Additional file 2) and UV-VIS spectroscopy. In the $\mathrm{CDCl}_{3}$ solution, only the presence of the cis keto-enol form of 2 has been found. The symmetric conformations of enolone fragment of molecules were determined on the basis of equal chemical shifts for both carbonyl carbon atoms in the ${ }^{13} \mathrm{C}$ NMR spectra. The ${ }^{13} \mathrm{C}$ NMR prediction $\left({ }^{13} \mathrm{C}\right.$ NMR were predicted by $\mathrm{ACD} / \mathrm{NMR}$ Processor and NMR Workbook Suite v.12. program) of the cis ketoenol form of 2,6-dimethoxy curcuminoid 2d shows for enolic moiety two signals at 186.6 and $173.1 \mathrm{ppm}$ and for $2 \mathrm{e}$ derivative at 187.4 and $175.0 \mathrm{ppm}$ (Figure $7 \mathrm{~b}$ ). In the obtained ${ }^{13} \mathrm{C}$ NMR spectra, separate signals are not seen because of rapid tautomerization between both tautomers. Instead, only one signal is seen at $184.7 \mathrm{ppm}$ for $\mathbf{2 d}$ and at $183.2 \mathrm{ppm}$ for $\mathbf{2 e}$ (Figure $7 \mathrm{a}$ ). The fact that both polymorph forms of $2 \mathbf{e}$ gave the same ${ }^{13} \mathrm{C}$ NMR spectra in solution once again confirms the thesis that the situation in solution is quite different from those in solid state.

As the chemical shifts for carbonyl atom in other isomers are also very similar to those of $\mathbf{2 d}$ and $\mathbf{2 e}$, see Table 1, the substituents bonded at the carbonyl atom, being in our cases different only in position of methoxy groups in the phenyl ring, have only a small influence on the conformation of the central enolone fragment in the solution. The small influence of substituents on the conformation of the enolone fragment can also be seen from relative small difference for chemical shifts of the enolic proton, being in all cases between 15.83 and $16.23 \mathrm{ppm}$.

Using the correlation of chemical shift for the enolic proton and hydrogen-bond strength, we can establish that the positions of the methoxy groups have little

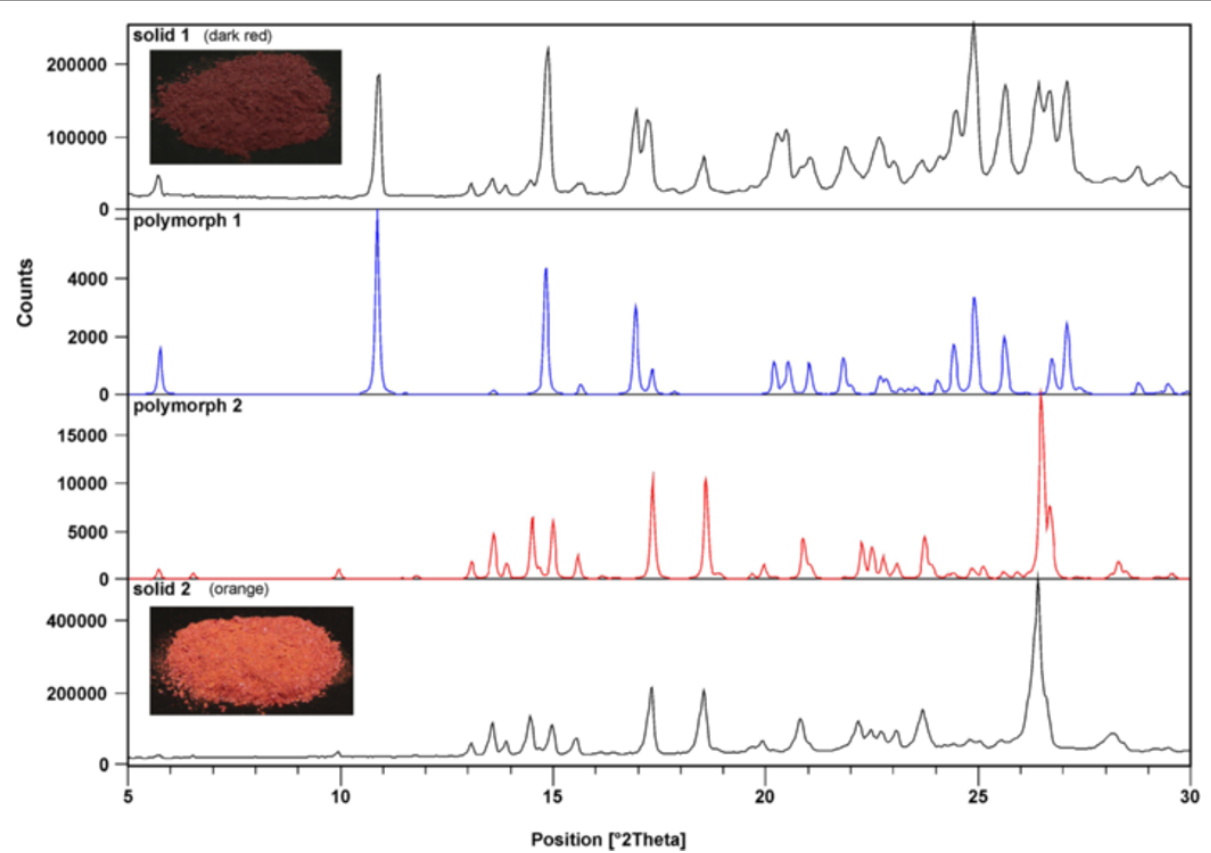

Figure 3 XRD diagrams of 2e. Measured pattern of solid 1, solid 2 and calculated pattern from X-ray structure of polymorph 1, polymorph 2. 
influence on the enolic $\mathrm{H}$-bond strength. To establish how the position of methoxy groups bonded in a phenyl ring influence the conformation of whole molecules, UV-VIS spectra of all dimethoxy curcuminoid isomers were carried out using $5.0 \cdot 10^{-6} \mathrm{M} \mathrm{CH}_{2} \mathrm{Cl}_{2}$ solution (Figure 8). Isomers 2,3- $\mathrm{diOCH}_{3}$ (2a); 2,6- $\mathrm{diOCH}_{3}$ (2d) and $3,5-\mathrm{diOCH}_{3}$ (2f) have absorption maximums at shorter wavelengths (but very close to each other), while the absorption maximum for 2,4- $\mathrm{diOCH}_{3}(\mathbf{2 b})$; $2,5-\mathrm{diOCH}_{3}$ (2c) and 3,4- $\mathrm{diOCH}_{3}(\mathbf{2 e})$ are at longer wavelengths. Let us suppose that the influence of the methoxy groups bonded in a phenyl ring (strong electron donating group) at orto and para positions are higher from that of a meta position. For this reason, it is very difficult to maintain that only the positions of
2, 4 and 6 in dimethoxy curcuminoids contribute more to the $\pi$-delocalization of whole molecule than positions 3 and 5 . The planarity of molecules is also important and must be taken into account for the explanation the differences of absorption maximum in UV-VIS spectra. When the absorption spectra were carried out in $5.0 \cdot 10^{-6} \mathrm{M} \mathrm{CH}_{3} \mathrm{CN}$ solution, a small hypsochromic effect was observed (cca. 2-4 nm).

Cis keto-enol tautomers of dimethoxy curcuminoids in solution can be characterized by resonance-assisted intramolecular hydrogen bond and a low barrier potential well in the proton transfer pathway between two equivalent tautomeric forms. The $\mathrm{H}$-centred conformation represents the transition state. Identical $\mathrm{C}-\mathrm{O}$ groups of the enolone fragment guarantee the equal

(a)

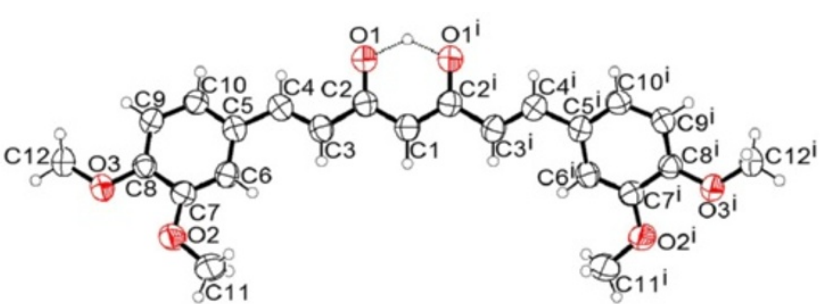

Hydrogen-bonding geometry $\left(\mathrm{A},{ }^{\circ}\right)$

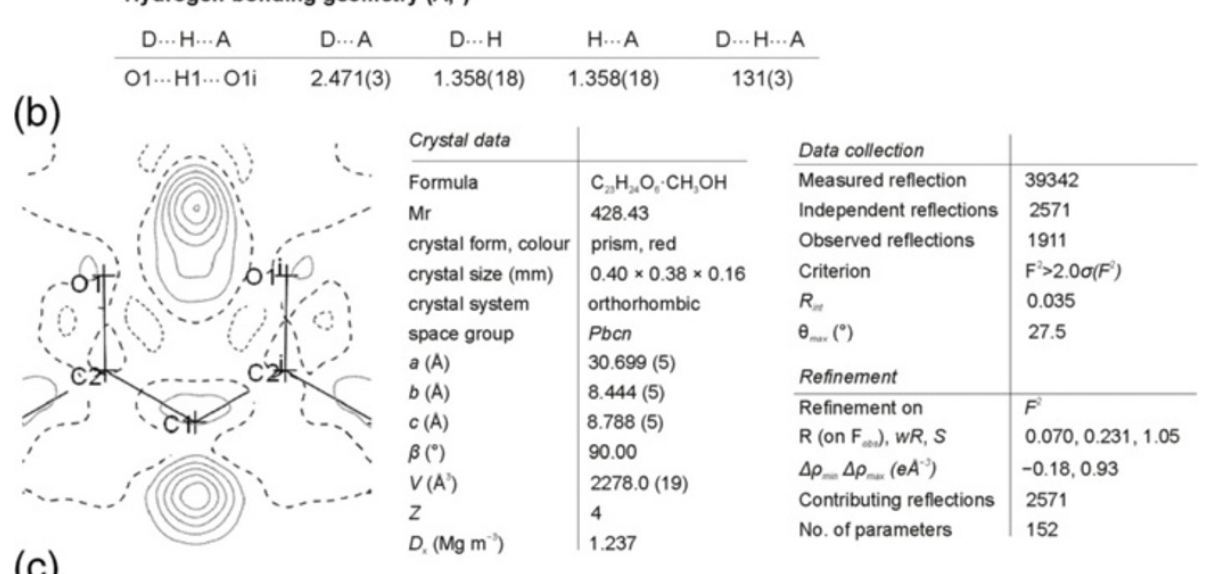

(c)

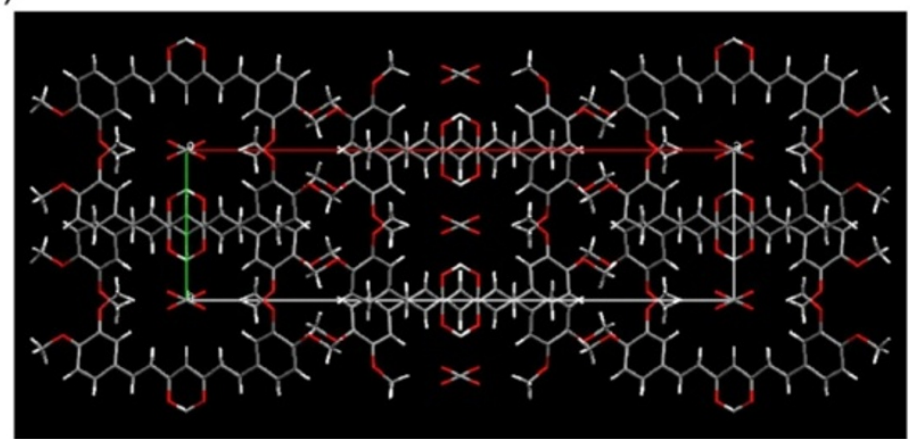

Figure 4 X-ray structure of 2e, polymorph 1. (a) ORTEP view of 2e, polymorph 1 (50\% probability displacement ellipsoids). Hydrogen atoms are drawn as circles of arbitrary radii. [Symmetry code (i) $-x, y,-z+12$ ] (b) Difference-Fourier map plotted in the mean plane of labelled atoms. (c) Packing of molecules of 2e (polymorph 1) as viewed along $c$ axis. In the channels oriented along $c$ axis are also molecules of solvent, methanol. 
basicity of both oxygen atoms, necessary for equal sharing of the proton.

\section{Theoretical investigation of compounds 2a-f}

To clarify the reason for changes in absorption maximum in the UV-VIS spectra when the position of methoxy groups are different in curcuminoids, the theoretical calculation in the gas phase with optimized geometries in the $6-31 G(\mathrm{~d}, \mathrm{p})$ basis at the DFT/B3LYP level of theory were carried out. We determined that the total energy is different and is the highest in the case of the 2,3- $\mathrm{diOCH}_{3}$ (2a) isomer and the lowest in the case of the 2,4- $\mathrm{diOCH}_{3}$

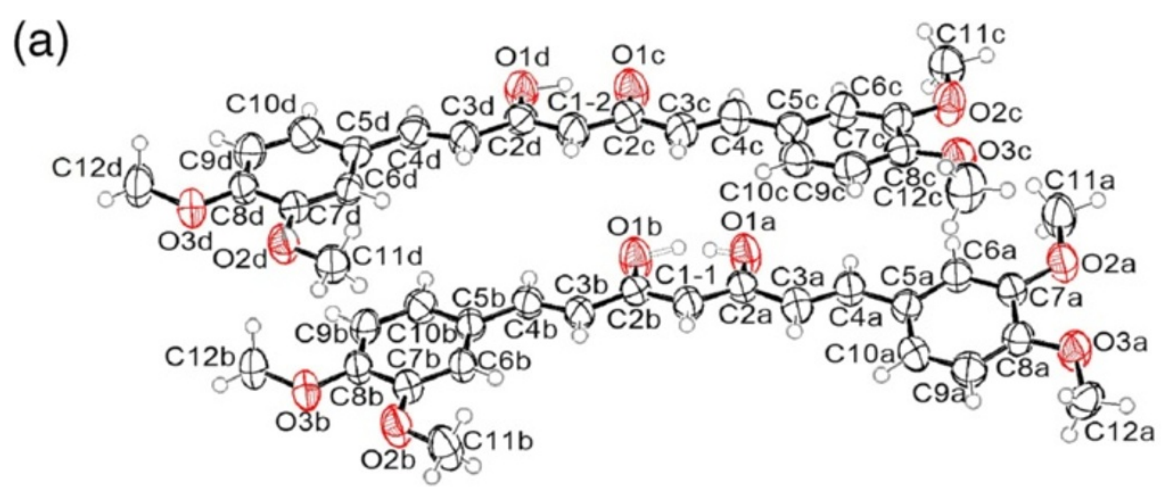

Hydrogen-bonding geometry $\left(\AA,^{\circ}\right)$

\begin{tabular}{ccccc}
$\mathrm{D}-\mathrm{H} \cdots \mathrm{A}$ & $\mathrm{D} \cdots \mathrm{A}$ & $\mathrm{D}-\mathrm{H}$ & $\mathrm{H} \cdots \mathrm{A}$ & $\mathrm{D}-\mathrm{H} \cdots \mathrm{A}$ \\
\hline $\mathrm{O} 1 \mathrm{~d}-\mathrm{H} 1 \mathrm{dc} \cdots \mathrm{O} 1 \mathrm{c}$ & $2.505(2)$ & 1.02 & 1.56 & 152
\end{tabular}
O1b::: H1b H1a:::01a 2.495(2)

(b)

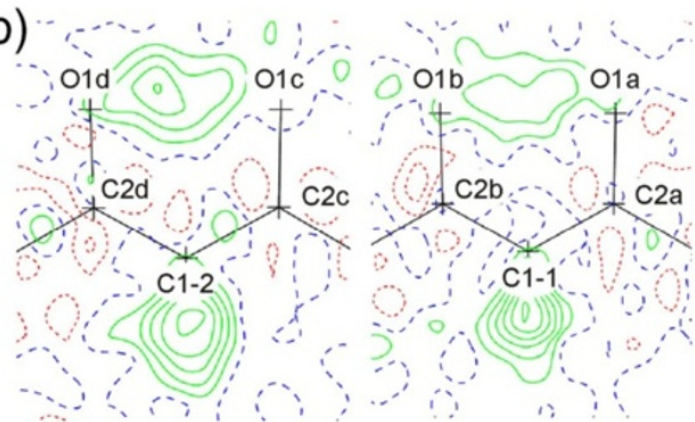

(c)

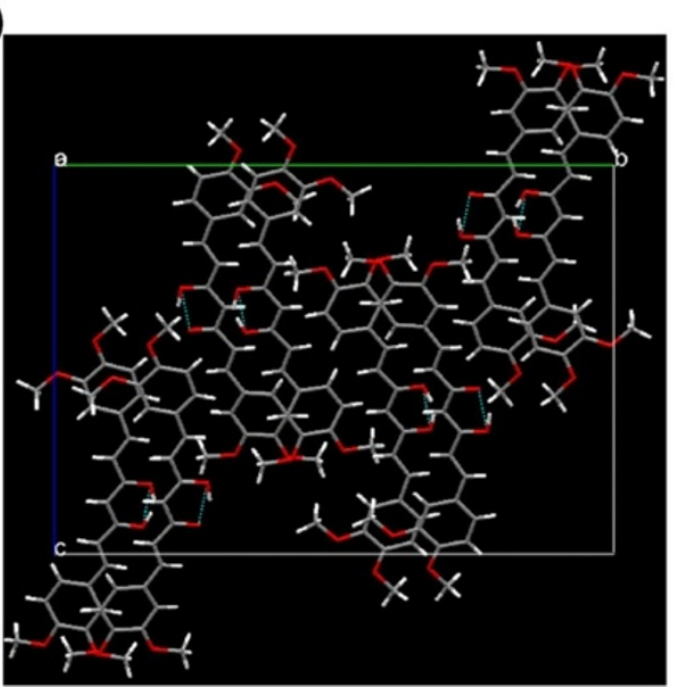

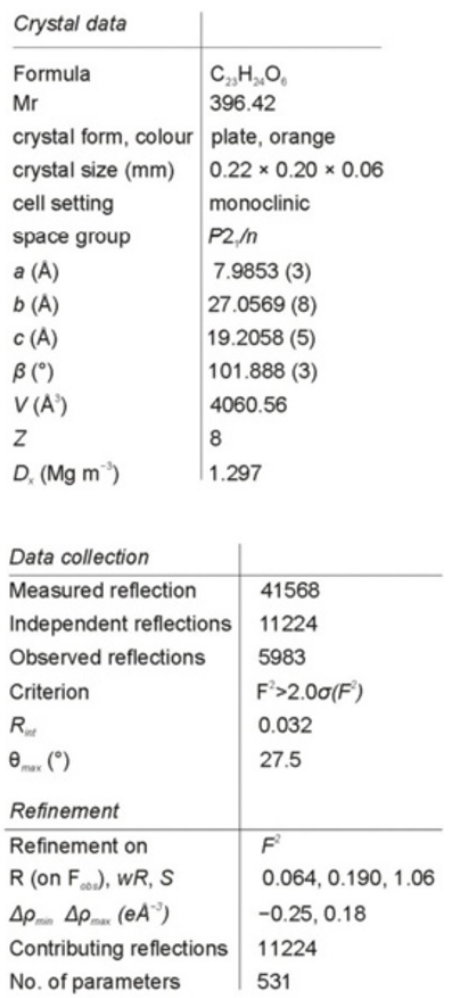

Figure 5 X-ray structure of 2e, polymorph 2. (a) ORTEP view of 2e, polymorph 2 (50\% probability displacement ellipsoids). Hydrogen atoms are drawn as circles of arbitrary radii. (b) Difference-Fourier maps plotted in the mean plane of labelled atoms. (c) Packing of molecules of 2e (polymorph 2) as viewed along a axis. 


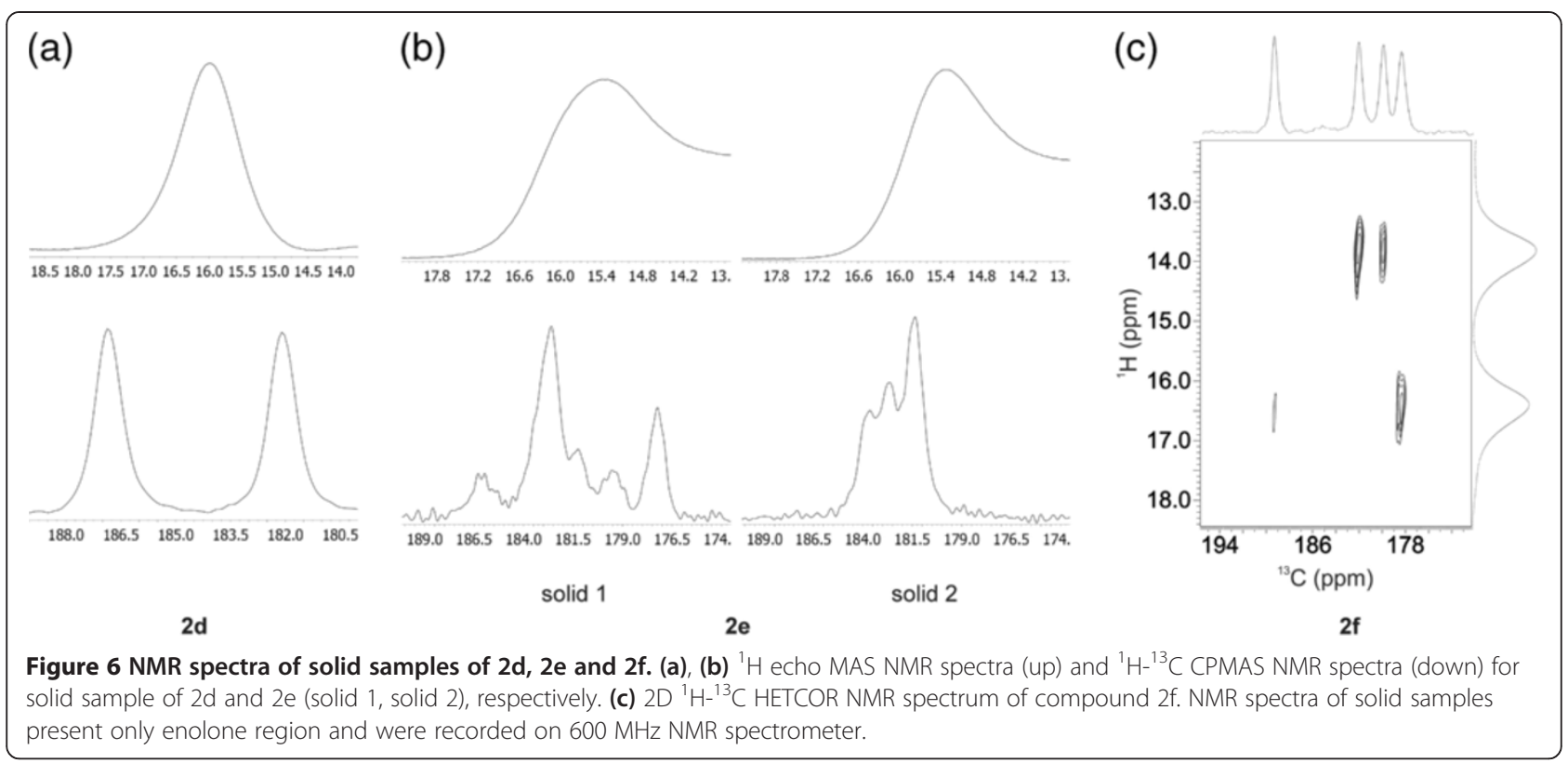

(2b) isomer. The relative energies for all isomers in comparison to 2,4- $\mathrm{diOCH}_{3}(\mathbf{2 b})$ are also given, see Figure 9.

On the basis of the HOMO and LUMO analyses, it can be seen that the HOMO is delocalized over the entire structure in a $\pi$ molecular orbital while LUMO, which is predominantly $\pi^{*}$ in character, also shows considerable delocalization (Figure 9). The oxygen of both methoxy groups are involved in the HOMO except in the case of $2,3-\mathrm{diOCH}_{3}$ (2a) in which only the oxygen atoms on position 2 is slightly involved and in 3,5- $\mathrm{diOCH}_{3}$ (2f) in which $\mathrm{HOMO}$ practically does not involve both of methoxy groups. In contrast, in LUMO the oxygen of methoxy group bonded at position 4 in the phenyl ring slightly participates in the case of 2,4- $\mathrm{diOCH}_{3}(\mathbf{2 b})$ and 3,4- $\mathrm{diOCH}_{3}(\mathbf{2 e})$ isomers.
Small participation of electrons from the oxygen of the methoxy groups can also be seen from calculated natural atomic charges being in all cases very similar $(-0.52 \pm 0.01)$, except in the case of $2,3-\mathrm{diOCH}_{3}(\mathbf{2 a})$ in which the charge an oxygen atom of the methoxy group bonded at position 2 and 3 is slightly higher, -0.55 .

The energy gaps between HOMO and LUMO are similar for 2,3- $\mathrm{diOCH}_{3}$ (2a), 2,6- $\mathrm{diOCH}_{3}$ (2d), and $3,5-\mathrm{diOCH}_{3}(\mathbf{2 f})$ on one side and for 2,4-- $\mathrm{diOCH}_{3}(\mathbf{2 b})$, 2,5- $\mathrm{diOCH}_{3}$ (2c), and 3,4- $\mathrm{diOCH}_{3}$ (2e) on the other side, and decrease from $3,5-\mathrm{diOCH}_{3}$ (2f) $(338.82 \mathrm{~kJ} /$ mol) to $3,4-\mathrm{diOCH}_{3}(\mathbf{2 e})(307.96 \mathrm{~kJ} / \mathrm{mol})$. These calculated data are in nearly agreement with experimental observation in UV-VIS spectra, in which the absorption maximums for 2,3- $\mathrm{diOCH}_{3}(\mathbf{2 a}), 2,6-\mathrm{diOCH}_{3}(\mathbf{2 d})$

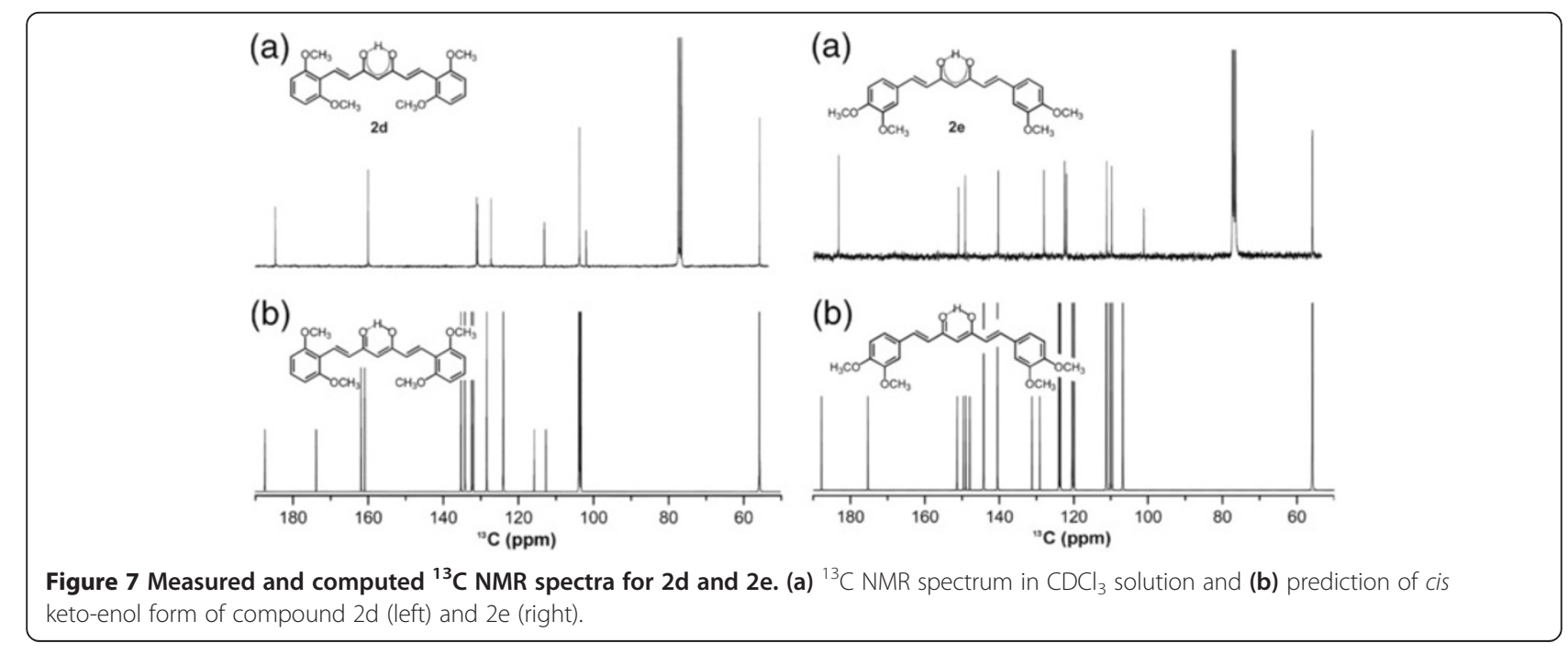


and 3,5- $\mathrm{diOCH}_{3}$ (2f) appear at lower wavelength than the absorption maximums for 2,4- (2b); 2,5- (2c) and 3,4- $\mathrm{diOCH}_{3}(\mathbf{2 e})$ isomers, see Figure 8.

Natural atomic charges computed for the enol isomers of curcuminoids in the gas phase at both oxygen atoms of the carbonyl group correlate with the energy of LUMO. The charges are higher in the case of the 2,6- $\mathrm{diOCH}_{3}(\mathbf{2 d})$ isomer with the highest LUMO energy $(-167.09 \mathrm{~kJ} / \mathrm{mol})$ and lower for the 3,5- $\mathrm{diOCH}_{3}$ (2f) isomer in which the LUMO energy is the lowest and the stabilization the most pronounced. All natural atomic charges for the enolone part of dimethoxy curcuminoid isomers are given in the Figure 10.

Comparison computed HOMO and LUMO orbitals of syn-enol form of curcumin in the gas phase [17] with HOMO, LUMO orbitals of dimethoxy curcuminoids shows, firstly, that in both cases the HOMO is delocalized over the entire structure and, secondly, that the methoxy groups in curcumin are slightly involved in the HOMO, while the contribution of methoxy groups in dimethoxy curcuminoids depend on its position. In all mentioned cases, the methoxy groups practically do not participate in LUMO, as expected. The HOMO-LUMO gap of curcumin $(313.6 \mathrm{~kJ} / \mathrm{mol})$ is nearly the same as in $2,5-\mathrm{diOCH}_{3}(313.3 \mathrm{~kJ} / \mathrm{mol})$ and $2,4-\mathrm{diOCH}_{3}(314.9 \mathrm{~kJ} /$ $\mathrm{mol})$, slightly higher than in 3,4- $\mathrm{diOCH}_{3}(308.0 \mathrm{~kJ} / \mathrm{mol})$ and lower than in other isomers.

Energies obtained at the optimized geometries in the aqueous solution and the gas phase using DFT/B3LYP and $6311-G(2 \mathrm{~d}, 2 \mathrm{p})$ basis sets for syn-enol tautomer of curcumin show that the total energy stabilization in water is $19.5 \mathrm{kcal} / \mathrm{mol}(81.9 \mathrm{~kJ} / \mathrm{mol})$, the dipole moment change from 7.67 D to $10.77 \mathrm{D}$, while the HOMO-LUMO gap is lower in the water solution by $0.18 \mathrm{eV}$ (from 3.25 to $3.07 \mathrm{eV}$ ) [17].

From that reason we found it necessary to compute total energies, dipole moments and HOMO-LUMO gaps for all isomers of dimethoxy curcuminoids in $\mathrm{CH}_{2} \mathrm{Cl}_{2}$ solutions.

As seen from Table 2 the total energy stabilization of syn-enolic form of all dimethoxy curcuminoids in $\mathrm{CH}_{2} \mathrm{Cl}_{2}$ are only slightly different and varied from 63.1 to $70.8 \mathrm{~kJ} / \mathrm{mol}$ and is lower than in the case of curcumin in water [17] which can be attributed to a lower dipole moment of dimethoxy curcuminoids in dichloromethane besides the smaller polarity of dichloromethane.

For all isomers of dimethoxy curcuminoids dipole moments are higher in the solution than in the gas phase. As the computationally determined HOMOLUMO gaps in $\mathrm{CH}_{2} \mathrm{Cl}_{2}$ solution in comparison with those in the gas phase are lower for all isomers the absorption maxima are red shifted. But it is necessary to mention that much better correlations are obtained by direct comparison of the observed and calculated (using TDDFT/B3LYP and 631-G(d,p) basis sets) absorption maxima in UV-VIS spectra (Additional file 1: Figure S1).

\section{Halogenation of compounds 2a-f}

Why halogenations of dimethoxy curcuminoids? There are several reasons. a) These compounds have two reactive positions for electrophilic halogenations: the activated phenyl ring and the activated methylene group. b) If halogenation takes place on the activated phenyl ring we will be able to determine how the halogen atom participates in electron density distribution in a conjugated system of curcuminoids. c) If halogenation takes place on an activated methylene position we will be able to determine how the halogen atom influences the preferent tautomers of dimethoxy curcuminoids in solid phase and in solution. Halogenation of compounds 2a-f were carried out using the $\mathrm{NXS} / \mathrm{LiClO}_{4} / \mathrm{CH}_{3} \mathrm{CN}$ system (Figure 11).

First, we chlorinated 1,7-bis(3,5-dimethoxyphenyl)-1,6heptadiene-3,5-dione (2f) and determined the structure of product $3 \mathbf{f}$ on the bases of the spectroscopic data and the elemental analysis. In the ${ }^{1} \mathrm{H}$ NMR spectrum of $\mathbf{3 f}$, we observed almost all signals at slightly different chemical shifts as compared with the parent compound 2f, except the signal at $5.85 \mathrm{ppm}$ for the proton on the $\mathrm{C} 4$ position that disappears in 3f. From mass spectra showing $\mathrm{MH}^{+}$and $(\mathrm{MH}+2)^{+}$signals at $\mathrm{m} / \mathrm{z}=431$ and 433 with a relative intensity of $3: 1$, we determined that one chlorine atom was present in the molecule. Contrary to the results for 2-chloro-1-phenyl3-(3,5-dimethoxyphenyl)propane-1,3-dione [34], being in chloroform exclusively in a diketone form, we have found that a $\alpha$-chloro derivative $3 \mathbf{f}$ is present in cis keto-enol form in the chloroform solution (Additional file 2).

We also applied this protocol for bromination of $\mathbf{2 f}$ using NBS as a source of bromine in the presence of $\mathrm{LiClO}_{4}$ as catalyst. The reaction was also regioselective and took place exclusively at $\alpha$-position of 1,3-diketone moiety leading to $4 \mathbf{f}$ that was in cis keto-enol form in the $\mathrm{CDCl}_{3}$ solution (Additional file 2), as determined by ${ }^{1} \mathrm{H},{ }^{13} \mathrm{C}$ NMR and mass spectra.

To establish whether the position of methoxy group in the phenyl ring has any influence on the regioselectively of halogenation, bromination and chlorination, the reactions were carried out with all other isomers $2 \mathbf{2 a}, \mathbf{2 b}$; 2 c; 2d and 2e (Figure 11).

From the results obtained, we can determine that in all cases bromination and chlorination took place regioselectively on the $\alpha$-position in the 1,3-diketone moiety and that $\alpha$-halo products were present dominantly in cis keto-enol forms in the $\mathrm{CDCl}_{3}$ solution. The conformation of central keto-enol moiety was determined on the basis of ${ }^{1} \mathrm{H}$ and ${ }^{13} \mathrm{C}$ NMR spectra in $\mathrm{CDCl}_{3}$ solution. In the ${ }^{13} \mathrm{C}$ 
Table 1 Chemical shifts for enolic $\mathrm{H}$-atom and carbonyl carbon atom in cis keto-enol form of compounds 2, 3 and 4 in $\mathrm{CDCl}_{3}$ solution

\begin{tabular}{|c|c|c|c|c|c|c|c|c|}
\hline Comp. & $\delta(\mathrm{OH})$ & $\delta(\underline{C O})$ & Comp. & $\delta(\mathrm{OH})$ & $\delta(\underline{\mathrm{CO}})$ & Comp. & $\delta(\mathrm{OH})$ & $\delta(\underline{C O})$ \\
\hline $2 a$ & 15.91 & 183.6 & $3 a$ & 16.41 & 180.5 & $4 a$ & 16.86 & 181.3 \\
\hline $2 b$ & 16.19 & 183.8 & $3 b$ & 16.78 & 180.6 & $4 b$ & 17.21 & 181.5 \\
\hline $2 c$ & 15.96 & 183.6 & $3 c$ & 16.52 & 180.5 & $4 c$ & 16.96 & 181.4 \\
\hline $2 d$ & 16.23 & 184.7 & $3 d$ & 16.77 & 181.6 & $4 d$ & 17.19 & 182.4 \\
\hline $2 e$ & 16.02 & 183.2 & $3 e$ & 16.62 & 180.1 & $4 e$ & 17.05 & 181.0 \\
\hline $2 f$ & 15.83 & 183.2 & $3 f$ & 16.34 & 180.1 & $4 f$ & 16.74 & 181.0 \\
\hline
\end{tabular}

NMR spectra, signals for C3 and C5 appear at the same chemical shifts, showing that the enolic fragment of molecules must be symmetric. As in parent compounds, because of rapid tautomerization between both keto-enol forms, average signals for both carbonyl carbon atoms are seen. Due to the effect of halogen atoms bonded at the $\mathrm{C} 4$ position, chemical shifts for C3, C5 are a slightly different from those of the corresponding parent compounds (Table 1). In ${ }^{1} \mathrm{H}$ NMR spectra, chemical shifts of the enolic proton are higher than in parent compounds, showing that hydrogen-bond strength increases when a halogen atom (chlorine or bromine) is bonded at the $\mathrm{C} 4$ position. The slightly different electronic effect of chlorine versus bromine reflects in different $\mathrm{OH}$ chemical shifts being for bromo-substituted compounds cca $0.43 \mathrm{ppm}$ higher than for chloro compounds, see Table 1.

In some cases, up to $5 \%$ of diketone forms were also present in equilibrium in the $\mathrm{CDCl}_{3}$ solution. The content of the diketone forms was determined from the ${ }^{1} \mathrm{H}$ NMR spectra in which signals for the proton bonded at $\mathrm{C} 4$ position were observed. More detailed structure information about the diketone form being in equilibrium with enol form was determined using $2 \mathrm{D}$ NMR spectra. For example: in the case of the bromo derivative 4d, a new signal at $5.37 \mathrm{ppm}$ appears that shows correlation with the signal at $57.5 \mathrm{ppm}$ assigned to $\mathrm{C} 4$ in the HSQC spectrum, while in the HMBC spectrum H4 correlates with C2 (at 124.2 ppm) and C3 (190.2 ppm) atoms (Figure 12). The isolate yields and purity of all $\alpha$-halo compounds are very high and are given in Figure 11.

\section{Theoretical investigation of some chloro and bromo derivatives}

Comparison of UV-VIS spectra of parent compounds and its 4-chloro and 4-bromo derivatives shows a significant bathochromic shifts, which are in the range of 20-29 nm except in the case of $\mathbf{3 d}$ in which bathochromic shift is higher $(39 \mathrm{~nm})$ in the $5.0 \cdot 10^{-6} \mathrm{M} \mathrm{CH}_{2} \mathrm{Cl}_{2}$ solution (Figure 13).

The bonded halogen atoms contribute to the extension of the conjugated system, which is reflected in greater stabilization of the excited state in comparison to the ground state and in lowering of the energy gap between HOMO and LUMO. To confirm the aforementioned experimental statement, theoretical calculation of the completely optimized geometry of 4-chloro and 4-bromo derivatives of 2,6- $\mathrm{diOCH}_{3}, 3,4-\mathrm{diOCH}_{3}$, and 3,5- $\mathrm{diOCH}_{3}$ curcuminoids were done. Figure 14 shows the computed energetics, relative energy separations, the molecular orbital energy level diagrams and HOMO-LUMO gaps of

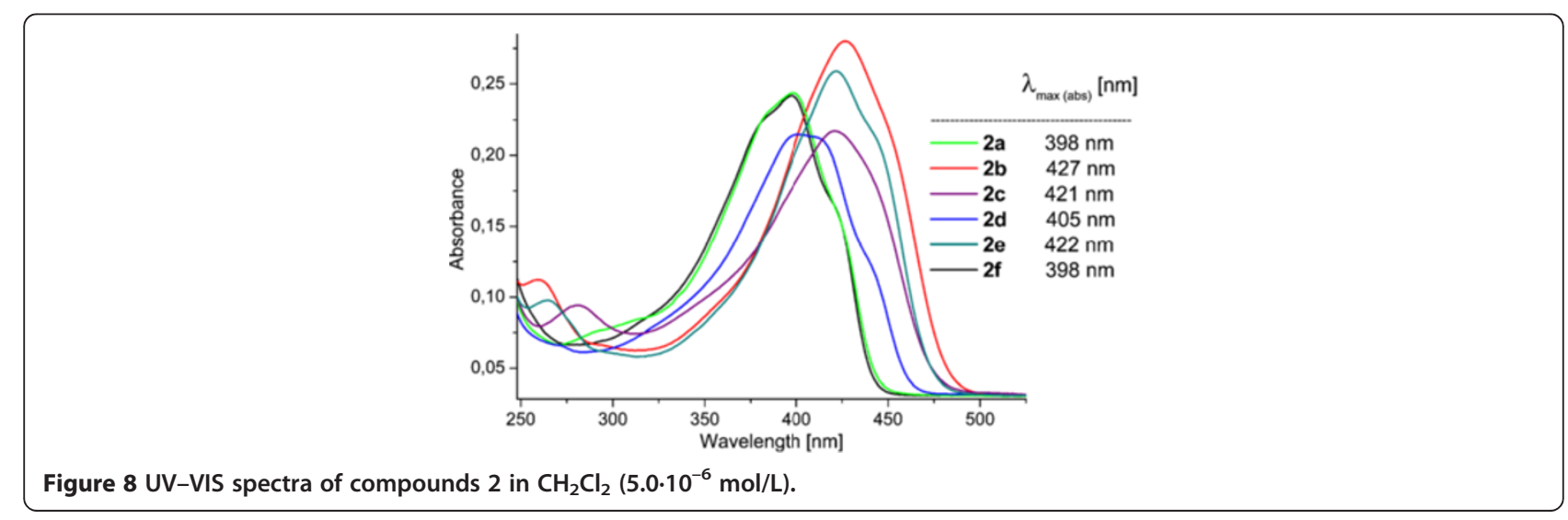


enolic forms of corresponding curcuminoids. As seen from the figures, the halogen atoms bonded at position 4 have no influence on the energy of HOMO, while the energy of LUMO is lower in comparison with parent compounds. The HOMO-LUMO gaps are independent from the type of halogen and are nearly the same for the chloro and bromo derivatives. As seen from data for absorption maxima in UV-vis spectra in Figure 13, theoretical calculations are in accord with experimental observation except in the case of $\mathbf{3 d}$.

The participation of electrons of the halogen atom can also be seen from the change of charges at atoms of the enolone part of molecules. In the case of chloro derivatives, small negative charges are present at the chlorine atom: -0.032 in $2,6-\mathrm{diOCH}_{3}(\mathbf{3 d}) ;-0.026$ in 3,4- $\mathrm{diOCH}_{3}$ (3e); -0.019 in $3,5-\mathrm{diOCH}_{3}$ (3f) while in bromo derivatives slightly positive charges are present on the bromine atom: 0.028 in 2,6- $\mathrm{diOCH}_{3}$ (4d); 0.036 in 3,4- $\mathrm{diOCH}_{3}$ (4e); and 0.045 in 3,5- $\mathrm{diOCH}_{3}$ (4f) (Figure 15). In contrast, the negative charges on $\mathrm{C} 4$ are drastically reduced while slight reductions of negative charges are observed at $\mathrm{O} 3$ and $\mathrm{O} 5$ atoms, showing calculated electrostatic potential maps of compounds $2 \mathbf{e}$, $3 \mathbf{e}$ and 4e in Additional file 1: Figure S3. The positive charges at C3 and C5 are also reduced, see Figure 15. The introduction of halogen atoms at position 4 is also reflected in the planarity of molecules. The dimethoxy substituted phenyl rings bonding at the carbonyl side of molecules are out of plane to a maximum of 5.7 degrees, reflecting a lower level of $\pi$-conjugation of these parts of the molecule in comparison with parent compounds (see molecular orbital diagrams for HOMOs in Figure 14).

The influence of halogen atoms at position $\mathrm{C} 4$ indicates in changes of total dipole moments being in all cases lower than in parent compounds, see Figure 15.

\section{Conclusions}

In conclusion: all six isomers of dimethoxy curcuminoids (2a-f) were prepared using a slight modification of the literature procedures. Higher yields were obtained with no additional purification made with flash chromatography. The structure of single crystal of compounds 2d and 2e (polymorphs 1 and 2) were determined by X-ray crystallography. The ORTEP drawing of compound $\mathbf{2 d}$ consists of the asymmetric unit, which contains one 2,6-dimethoxy curcuminoid molecule in cis keto-enol form. The solid sample of $2 \mathbf{e}$ contains polymorphs. The crystal structure of polymorph form 1 consists of the symmetric 3,4-dimethoxy curcuminoid molecule in which one half of the molecule is related symmetrically to the other half by a twofold axis. In contrast, the asymmetric unit of polymorph 2 contains two molecules of 3,4-diOCH${ }_{3} \cdot{ }^{1} \mathrm{H}$ MAS, ${ }^{13} \mathrm{C}$ CPMAS and ${ }^{1} \mathrm{H}_{-}{ }^{13} \mathrm{C}$ 2D HETCOR NMR measurements of solid state of 2,6- $\mathrm{diOCH}_{3}$ (2d); 3,4- $\mathrm{diOCH}_{3}$ (2e) and 3,5$\mathrm{diOCH}_{3}(\mathbf{2 f})$ show that in the case of $2,6-\mathrm{diOCH}_{3}$ only one tautomer is present, while in the case of 3,4$\mathrm{diOCH}_{3}$ and $3,5-\mathrm{diOCH}_{3}$ polymorphism exists. In the $\mathrm{CDCl}_{3}$ solution, all compounds 2 are present in forms that can be described as a coexistence of two equivalent tautomers being in fast equilibrium. The position of methoxy groups in compound $\mathbf{2}$ has little influence on the enolic hydrogen bond and on the position of absorption maximum in UV-VIS spectra. Theoretical calculation for all dimethoxy curcuminoids with complete geometry optimization in the $6-31 \mathrm{G}(\mathrm{d}, \mathrm{p})$ basis at DFT/ B3LYP level of theory for gas phase show that the total energy is different and that the energy gap between $\mathrm{HOMO}$ and LUMO are similar for $2,3-\mathrm{diOCH}_{3}$ (2a); 2,6- $-\mathrm{diOCH}_{3}$ (2d) and 3,5- $\mathrm{diOCH}_{3}$ (2f) in one side and for 2,4- $\mathrm{diOCH}_{3}(\mathbf{2 b})$; $2,5-\mathrm{diOCH}_{3}$ (2c) and 3,4- $\mathrm{diOCH}_{3}$

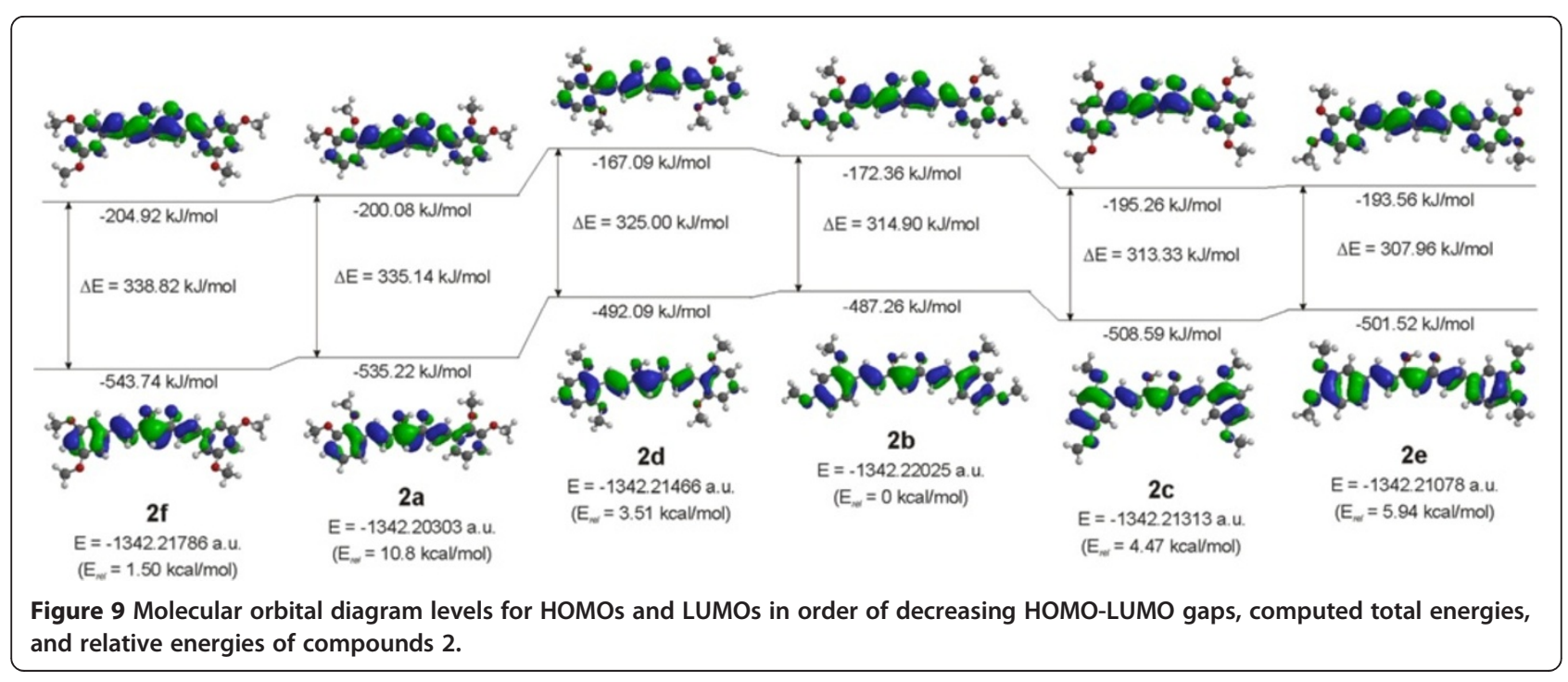




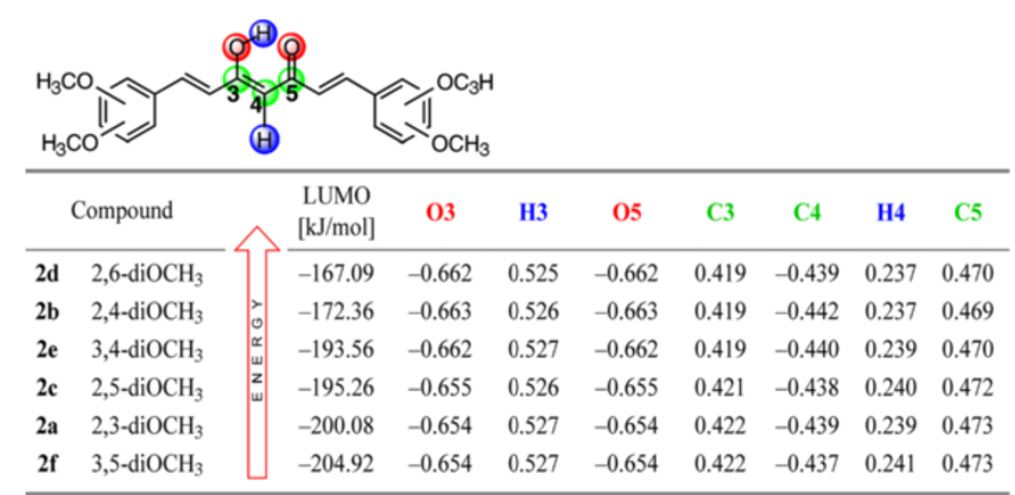

Figure 10 Computed LUMO energies and natural atomic charges for the enolone fragment of 2.

(2e) on the other side. Total energies, dipole moments and HOMO-LUMO gaps for all dimethoxy curcuminoids in $\mathrm{CH}_{2} \mathrm{Cl}_{2}$ solution were also calculated. The total energy stabilization varied from 63.1 to $70.8 \mathrm{~kJ} /$ mol, dipole moments are slightly higher in solution than in gas phase while HOMO-LUMO gaps are lower. Calculated UV-VIS spectra are mostly in agreement with the experimental observation in $\mathrm{CH}_{2} \mathrm{Cl}_{2}$ solution (Additional file 1: Figure S1). The low level of participation of electrons from the methoxy groups is reflected in very similar natural atomic charges on oxygen atoms. Chlorination and bromination on $\alpha$-position of 1,3diketone moiety of dimethoxy curcumin derivatives did not change the preferred form being cis keto-enol as in the parent compounds. The hydrogen-bond strength increases when chlorine or bromine atom is bonded at the C4 position. 4-Chloro- and 4-bromo derivatives in UV-VIS spectra show significant bathochromic shifts, which are in the range of $20-29 \mathrm{~nm}$ except in the case of 3d. The computed HOMO and LUMO orbitals show that the halogen atom (chlorine or bromine) bonded at C4 have no influence on the energy of HOMO, while the energy of LUMO are lower in comparison with parent compounds. The HOMO-LUMO gaps are independent of the type of halogen. The introduction of halogen atom at $\mathrm{C} 4$ is also reflected in the changes of total dipole moments.

\section{Experimental \\ Methods \\ Single-crystal structure analysis}

Crystals for X-ray of $\mathbf{2 d}$ and $\mathbf{2 e}$ (polymorph 2) were obtained from a mixture of $\mathrm{CH}_{2} \mathrm{Cl}_{2} /$ hexane, followed by slow evaporation in a refrigerator, while single crystals of compound $\mathbf{2 e}$ (polymorph 1) were prepared by recrystallization from $\mathrm{CH}_{3} \mathrm{OH}$, which was allowed to slowly evaporate at room temperature. Single crystal diffraction data for compounds $\mathbf{2 d}$ and $\mathbf{2 e}$ (polymorph 1) were collected on a Nonius Kappa CCD diffractometer at room temperature with a MoK $\alpha$ radiation and graphite

Table 2 Computed total energies, total energy stabilization, homo-lumo gaps and dipole moments of dimethoxy curcuminoids 2 in gas phase and $\mathrm{CH}_{2} \mathrm{Cl}_{2}$ solution

\begin{tabular}{|c|c|c|c|c|c|c|c|c|}
\hline \multicolumn{2}{|c|}{ Comp. } & \multirow{2}{*}{$\frac{\text { Energy }[\mathbf{k J} / \mathbf{m o l}]}{-3523956.5}$} & \multirow{2}{*}{$\frac{\text { Relative energy }[\mathrm{kJ} / \mathrm{mol}]}{0.0}$} & \multirow{2}{*}{$\frac{\text { HOMO }[\mathrm{kJ} / \mathrm{mol}]}{-535.2}$} & \multirow{2}{*}{$\frac{\text { LUMO }[\mathrm{kJ} / \mathrm{mol}]}{-200.1}$} & \multirow{2}{*}{$\frac{\text { HOMO-LUMO }[\mathrm{kJ} / \mathrm{mol}]}{335.1}$} & \multirow{2}{*}{$\frac{\lambda_{\max }[\mathrm{nm}]}{356.94}$} & \multirow{2}{*}{$\frac{\boldsymbol{\mu}[\mathrm{D}]}{4.47}$} \\
\hline $2 a$ & vacuum & & & & & & & \\
\hline & $\mathrm{CH}_{2} \mathrm{Cl}_{2}$ & -3524019.7 & -63.1 & -548.8 & -221.0 & 327.8 & 364.97 & 5.12 \\
\hline \multirow[t]{2}{*}{$2 b$} & vacuum & -3524001.7 & 0.0 & -487.3 & -172.4 & 314.9 & 379.89 & 0.55 \\
\hline & $\mathrm{CH}_{2} \mathrm{Cl}_{2}$ & -3524072.5 & -70.8 & -498.8 & -199.6 & 299.2 & 399.81 & 1.02 \\
\hline \multirow[t]{2}{*}{$2 c$} & vacuum & -3523983.0 & 0.0 & -508.6 & -195.3 & 313.3 & 381.79 & 2.15 \\
\hline & $\mathrm{CH}_{2} \mathrm{Cl}_{2}$ & -3524048.2 & -65.2 & -512.9 & -217.8 & 295.1 & 405.46 & 2.72 \\
\hline \multirow[t]{2}{*}{$2 d$} & vacuum & -3523987.1 & 0.0 & -492.1 & -167.1 & 325.0 & 368.08 & 4.01 \\
\hline & $\mathrm{CH}_{2} \mathrm{Cl}_{2}$ & -3524055.6 & -68.5 & -511.1 & -195.2 & 315.9 & 378.65 & 5.03 \\
\hline \multirow[t]{2}{*}{$2 e$} & vacuum & -3523976.9 & 0.0 & -501.5 & -193.6 & 307.9 & 388.45 & 3.57 \\
\hline & $\mathrm{CH}_{2} \mathrm{Cl}_{2}$ & -3524044.3 & -67.4 & -505.4 & -215.2 & 290.2 & 412.22 & 4.49 \\
\hline \multirow[t]{2}{*}{$2 f$} & vacuum & -3523995.5 & 0.0 & -543.7 & -204.9 & 338.8 & 353.07 & 4.99 \\
\hline & $\mathrm{CH}_{2} \mathrm{Cl}_{2}$ & -3524061.7 & -66.2 & -551.4 & -225.5 & 325.9 & 367.03 & 6.17 \\
\hline
\end{tabular}




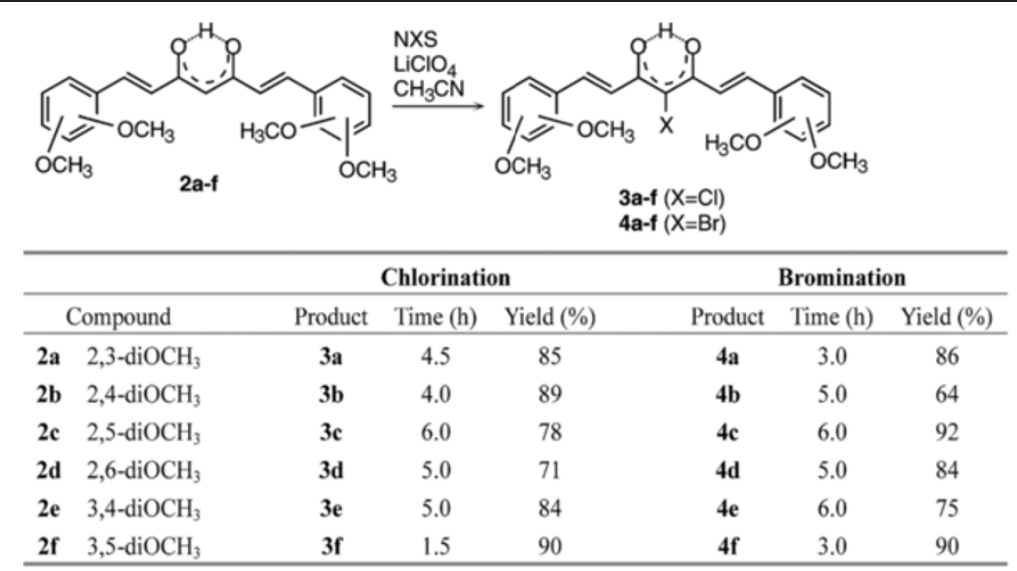

Figure 11 Halogenation of compound 2.

monochromator. The data were processed using the DENZO program. The data for compound 2e (polymorph 2) have been collected on a Agilent SuperNova dual source diffractometer with an Atlas detector at room temperature with MoKa radiation (0.71073 $\AA$ ) and processed using CrysAlis PRO software. All structures were solved with direct methods using SIR97. A full-matrix least-squares refinement on $F^{2}$ was employed with anisotropic temperature displacement parameters for all non-hydrogen atoms for all compounds. The $\mathrm{H}$ atom from enol hydroxy groups and the $\mathrm{H}$ atom bonded to (C4) atom were located from difference Fourier map in all compounds. These hydrogen atoms were refined freely with their isotropic displacement parameters. In the case of $\mathbf{2 e}$ (polymorph 2) the paremeters of these $\mathrm{H}$ atoms were not refiened. The remaining $\mathrm{H}$ atoms of all three dimethoxy curcuminoid molecules were placed at idealized, calculated positions and treated as riding, with $\mathrm{C}-\mathrm{H}=0.93$ for $\mathrm{C}\left(\mathrm{sp}^{2}\right)$ and $0.96 \AA$ for methyl group and $U_{\text {iso }}(\mathrm{H})=1.2 U_{\text {eq }}(\mathrm{C})$ or $1.5 U_{\text {eq }}(\mathrm{C})$ for $\mathrm{C}\left(\mathrm{sp}^{2}\right)$ and methyl group, respectively. Crystals of compound $\mathbf{2 e}$ (polymorph 1) also contain solvent molecules (methanol), which were located in the channels, running parallel $c$ axis. These methanol molecules are disordered and consequently their $\mathrm{H}$ atoms were not located. The SHELXL97 program was used for structure refinement and interpretation. Drawings of the structures were produced using the ORTEP-3, Platon and Mercury programs. Details of the crystal data, data collection, and refinement parameters are listed in Figures 2, 4 and 5. Structural and other crystallographic data have also been deposited with the Cambridge Crystallographic Data Centre as supplementary publication number CCDC 858801 (2d, Additional file 3) \& 858802 (2e polymorph 1, Additional file 4) \& 934715 (2e polymorph 2, Additional file 5). A copy of the data can be obtained, free of charge, on application to CCDC, 12 Union Road, Cambridge, CB2 1EZ, UK [fax: +44 (0)-1223-336033 or e-mail: deposit@ccdc.cam.ac.uk.

\section{XRD measurements}

X-ray powder diffraction data of solid 1, 2 and 3 were collected using a PANalytical X'Pert PRO (HTK) diffractometer with $\mathrm{CuK \alpha}$ radiation. The room temperature reflection data were acquired from $2 \Theta$ angles of $5^{\circ}$ to $30^{\circ}$ in steps of $0.034^{\circ}$.

\section{Solid-state NMR measurements}

NMR spectra of solid samples were recorded on a Varian NMR System $600 \mathrm{MHz}$ NMR spectrometer equipped with $3.2 \mathrm{~mm}$ NB Double Resonance HX MAS Solids Probe. Larmor frequencies of protons and carbon nuclei were 599.64 MHz and 150.79, respectively. The ${ }^{1} \mathrm{H}$ MAS NMR spectra were externally referenced using adamantane. The ${ }^{13} \mathrm{C}$ CPMAS NMR spectra were externally referenced using hexamethylbenzene (HMB). All samples were spun at the magic angle with $20 \mathrm{kHz}$ during ${ }^{1} \mathrm{H}$ measurement and $16 \mathrm{kHz}$ during ${ }^{13} \mathrm{C}$ measurements. Proton spectra were acquired using a spin echo sequence. The repetition delay in all experiments was $5 \mathrm{~s}$. The number of scans was 16. The pulse sequence used for acquiring carbon spectra was a standard cross-polarization MAS pulse sequence with high-power proton decoupling during acquisition. The repetition delay in all experiments was $5 \mathrm{~s}$ and the number of scans was between 1000 and 1620. A 2D ${ }^{1} \mathrm{H}^{13} \mathrm{C}$ HETCOR NMR spectrum was acquired at 16 kHz MAS. Ramp CP transfer with duration of $500 \mu \mathrm{s}$ was used.

\section{Theoretical calculation}

A theoretical investigation of all species were optimized at the density functional (DFT) level of theory employing the B3LYP/6-31G(d,p) model. Complete 

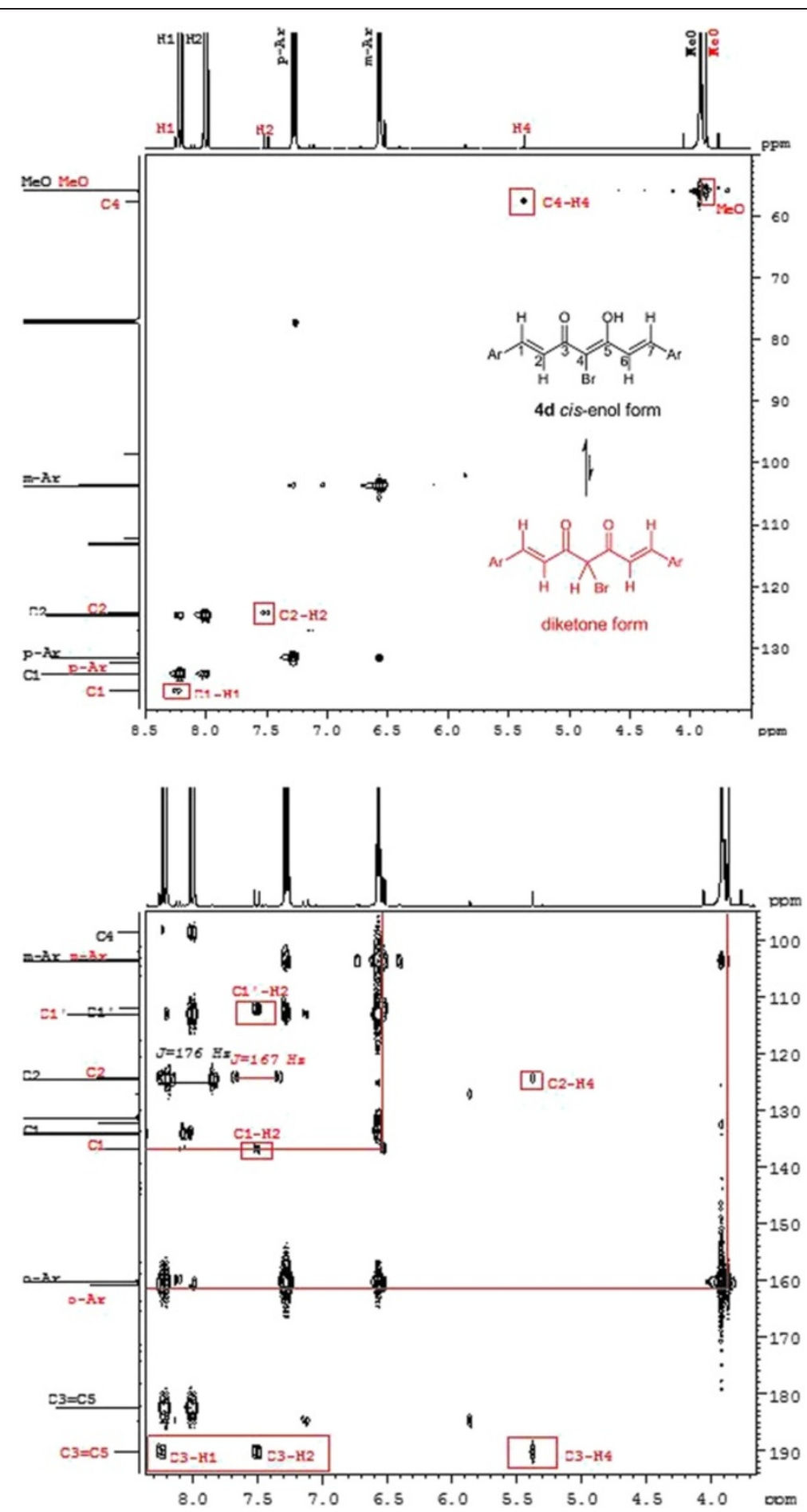

Figure 12 2D Spectra of 4d. (Top) Portion of the HSQC spectrum of $4 \mathrm{~d}$ at $302 \mathrm{~K}, 500 \mathrm{MHz}$ in $\mathrm{CDCl}_{3}$ solution. (Bottom) Portion of the HMBC spectrum.

geometry optimization was performed for the groundstate structures in the gas phase and $\mathrm{CH}_{2} \mathrm{Cl}_{2}$ solutions of all the molecular systems considered. For the optimized geometries, the Mulliken, natural, and electrostatic atomic charges from the electrostatic potential were calculated. The Spartan'08 suite of quantum chemical programs was used to perform all the calculations, molecular orbital diagrams for HOMOs and LUMOs, the graphic display of the electrostatic potential maps (isovalue $=0.02$; property colors range 


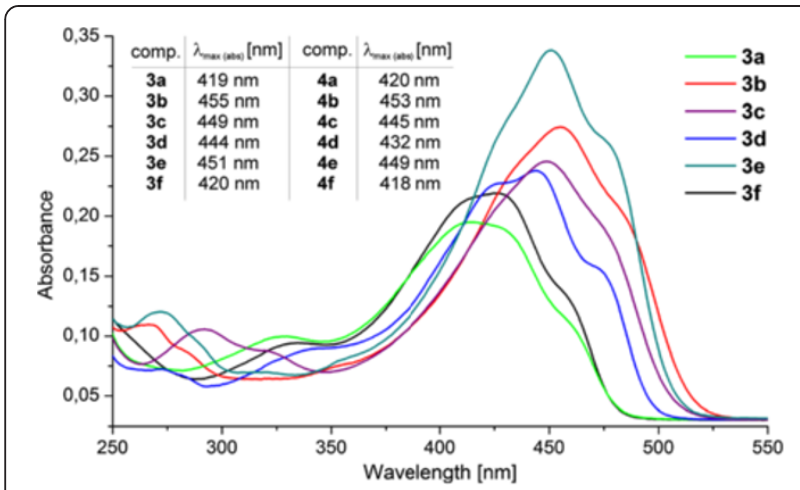

Figure 13 UV-VIS spectra of compounds 3 compared with tabulated absorption maxima of bromo-derivatives (4) in $\mathrm{CH}_{2} \mathrm{Cl}_{2}\left(5.0 \cdot 10^{-6} \mathrm{~mol} / \mathrm{L}\right)$.

from -90 to $65 \mathrm{~kJ} / \mathrm{mol}$ ). Theoretical UV-vis spectra were computed by TDDFT/B3LYP/6-31G(d,p) model and visualized using Gaussian function.

\section{Characterization of compounds}

Absorption spectra were recorded with a Lambda 750 UV-vis spectrophotometer from Perkin Elmer. NMR Spectra were recorded at $302 \mathrm{~K}$ with a Bruker Avance DPX 300 spectrometer operating at $300 \mathrm{MHz}$ and 75 $\mathrm{MHz}$ for ${ }^{1} \mathrm{H}$ and ${ }^{13} \mathrm{C}$, and Bruker Avance III 500 spectrometer operating at $500 \mathrm{MHz}$ and $126 \mathrm{MHz}$ for ${ }^{1} \mathrm{H}$ and ${ }^{13} \mathrm{C}$, respectively. Proton and carbon spectra were referenced to TMS as the internal standard. Chemical shifts are given on the $\delta$ scale (ppm). Coupling constants $(J)$ are given in $\mathrm{Hz}$. Mass spectra and high-resolution mass spectra were obtained with a Q-TOP Premier instrument. Data are reported as $m / z$ (relative intensity). Infrared spectra were recorded on a BIO-RAD Excalibur Series spectrophotometer using samples in potassium bromide disks. Elemental analyses were performed with a Perkin-Elmer 2400 Series II CHNS/O Analyzer. All spectral data obtained for new compounds are reported here. Melting points were measured with a Büchi 535 .

\section{General procedure for 1,7-bis(dimethoxyphenyl)-1, 6-heptadiene-3,5-dione}

Corresponding dimethoxy benzaldehyde (3.32 g, $20 \mathrm{mmol}$ ) was dissolved in ethyl acetate $(10-20 \mathrm{~mL})$ and tributylborate $(5.94 \mathrm{~mL}, 22 \mathrm{mmol})$ was added. The reaction mixure was heated to $75^{\circ} \mathrm{C}$. 2,4-Pentanedione (1.03 $\mathrm{mL}, 10 \mathrm{mmol}$ ) and powdery boric anhydride (0.52 g, $7.5 \mathrm{mmol})$ were mixed separately, carefully heated with stirring to obtain a paste, and added to the mixture of dimethoxybenzaldehyde and tributyl borate. The reaction mixture obtained was heated with stirring for 4.5 hours at $75^{\circ} \mathrm{C}$, then cooled to room temperature; $n$-butylamine $(0.25 \mathrm{~mL}, 2.5 \mathrm{mmol})$ in ethyl acetate $(2.5 \mathrm{~mL})$ was then slowly added.
Stirring at room temperature continued during the night. The reaction mixture was quenched with the addition of $0.4 \mathrm{~N} \mathrm{HCl}(15 \mathrm{~mL})$, heated for 1 hour at $60^{\circ} \mathrm{C}$, then cooled on ice, and the solid residue filtered off and washed several times with methanol. The products obtained (2a, $2.06 \mathrm{~g}$ (52\%); 2b, $2.45 \mathrm{~g}$ (62\%); 2c, 2.53 g (64\%); 2d, 2.77 g (70\%); 2e, 1.70 g (43\%); 2f, $1.66 \mathrm{~g}(42 \%))$ were pure enough to yield satisfactory spectroscopic data (see Additional file 1) and elemental analysis; no additional purification by flash chromatography was necessary.

\section{General procedure for halogenations}

Compound 2 (396 mg, $1 \mathrm{mmol}$ ) was dissolved in $\mathrm{CH}_{3} \mathrm{CN}(40 \mathrm{~mL}), \mathrm{LiClO}_{4}(64 \mathrm{mg}, 0.6 \mathrm{mmol})$ was added, and the resulting mixture was stirred $10 \mathrm{~min}$ at room temperature. An acetonitrile solution of NCS (147 mg, $1.1 \mathrm{mmol}$ ) or NBS (196 mg, $1.1 \mathrm{mmol}$ ) was slowly added and stirring continued for the corresponding time, given in Figure 11, at room temperature. The product precipitate was filtered off. The filtrate was evaporated and dissolved in methanol. After being refrigerated overnight, an additional quantity of pure product was obtained (in some cases, additional crystallization from the mixture of $\mathrm{CH}_{2} \mathrm{Cl}_{2}$ /hexane was done). Overall yields of pure products are given in Figure 11.

\section{(1E,6E)-1,7-bis(2,3-dimethoxyphenyl)-4-chloro-1, 6-heptadiene-3,5-dione (3a)}

Yellow-orange solid, mp 167.1-167.7 ${ }^{\circ} \mathrm{C} .{ }^{1} \mathrm{H}$ NMR $\left(\mathrm{CDCl}_{3}\right.$, $500 \mathrm{MHz}) \delta \mathrm{ppm} 16.41$ (s, $-\mathrm{OH}), 8.09$ (d, 2H, $J=15.9)$, 7.50 (d, $2 \mathrm{H}, J=15.9$ ), 7.28 (dd, $2 \mathrm{H}, J=8.0, J=1.0$ ), 7.09 (dd, $2 \mathrm{H}, J=8.0, J=8.0), 6.97$ (dd, $2 \mathrm{H}, J=8.0, J=1.0$ ), 3.90 (s, 6H), 3.89 (s, 6H). ${ }^{13} \mathrm{C} \mathrm{NMR}\left(\mathrm{CDCl}_{3}, 75 \mathrm{MHz}\right) \delta \mathrm{ppm}$ 180.5, 153.2, 148.9, 138.1, 129.2, 124.2, 121.2, 119.7, 114.3, $108.5,61.4,55.9$. IR (KBr) $v=1617,1578,1482,1428$, 1271, 1071, 998, 980, $735 \mathrm{~cm}^{-1}$. CIMS $(\mathrm{m} / z) 433.1$ $\left(\mathrm{MH}^{+}+2\right), 431.1\left(\mathrm{MH}^{+}\right)$. CI-HRMS for $\mathrm{C}_{23} \mathrm{H}_{24} \mathrm{ClO}_{6}^{+}$: calcd 431.1261, found 431.1258. EA for $\mathrm{C}_{23} \mathrm{H}_{23} \mathrm{ClO}_{6}$ : calcd $64.11 \% \mathrm{C}, 5.38 \% \mathrm{H}$; found $64.31 \% \mathrm{C}, 5.39 \% \mathrm{H}$.

\section{(1E,6E)-1,7-bis(2,4-dimethoxyphenyl)-4-chloro-1,} 6-heptadiene-3,5-dione (3b)

Orange solid, mp $169.9-170.8^{\circ} \mathrm{C} .{ }^{1} \mathrm{H}$ NMR $\left(\mathrm{CDCl}_{3}, 500\right.$ $\mathrm{MHz}) \delta \mathrm{ppm} 16.78(\mathrm{~s},-\mathrm{OH}), 8.04(\mathrm{~d}, 2 \mathrm{H}, J=15.8), 7.58$ $(\mathrm{d}, 2 \mathrm{H}, J=8.6), 7.40(\mathrm{~d}, 2 \mathrm{H}, J=15.8), 6.54(\mathrm{dd}, 2 \mathrm{H}, J=8.6$, $J=2.3), 6.46(\mathrm{~d}, 2 \mathrm{H}, J=2.3), 3.90(\mathrm{~s}, 6 \mathrm{H}), 3.86(\mathrm{~s}, 6 \mathrm{H}) .{ }^{13} \mathrm{C}$ $\mathrm{NMR}\left(\mathrm{CDCl}_{3}, 75 \mathrm{MHz}\right) \delta \mathrm{ppm} 180.6,163.1,160.3,138.2$, $130.5,117.8,117.4,107.7,105.6,98.3,55.6,55.5$. IR (KBr) $v=1596,1507,1462,1298,1276,1248,1212,1104,1031$, 970, $819 \mathrm{~cm}^{-1}$. CIMS $(\mathrm{m} / z) 433.1\left(\mathrm{MH}^{+}+2\right), 431.1\left(\mathrm{MH}^{+}\right)$. CI-HRMS for $\mathrm{C}_{23} \mathrm{H}_{24} \mathrm{ClO}_{6}^{+}$: calcd 431.1261, found 
(a)

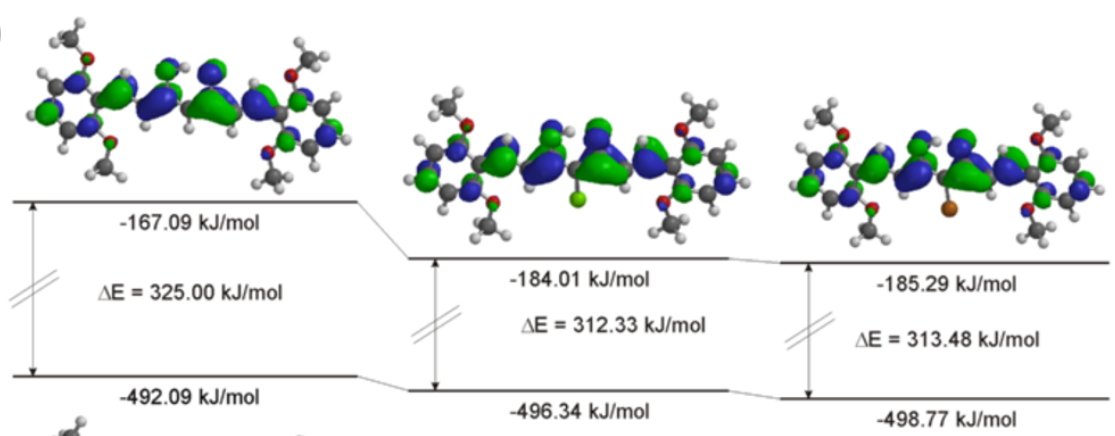

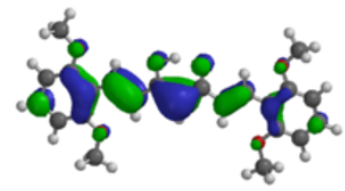

2d

$E=-1342.21466$ a.u.

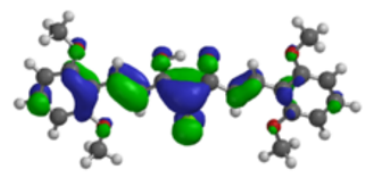

$3 d$

$E=-1801.80193$ a.u.

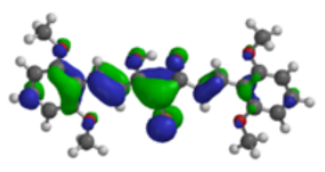

4d

$E=-3915.48657$ a.u

(b)

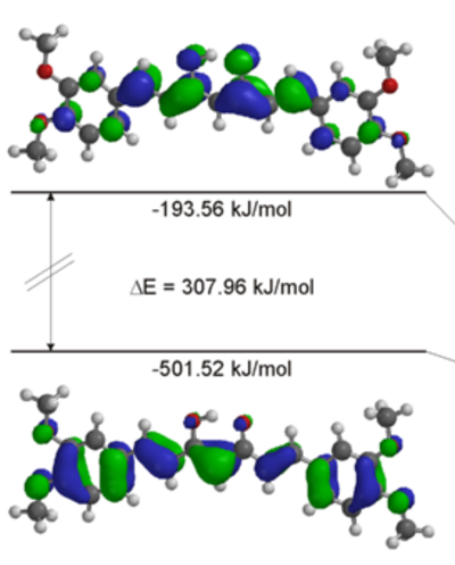

$2 \mathrm{e}$

$E=-1342.21078$ a.u.
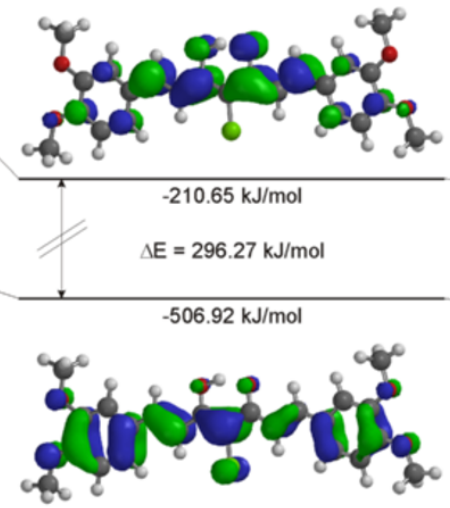

$3 e$

$E=-1801.79787$ a.u.
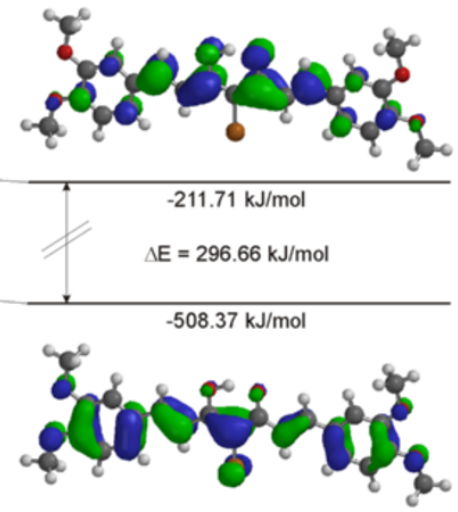

$4 \mathrm{e}$

$E=-3915.48251$ a.u.

(c)
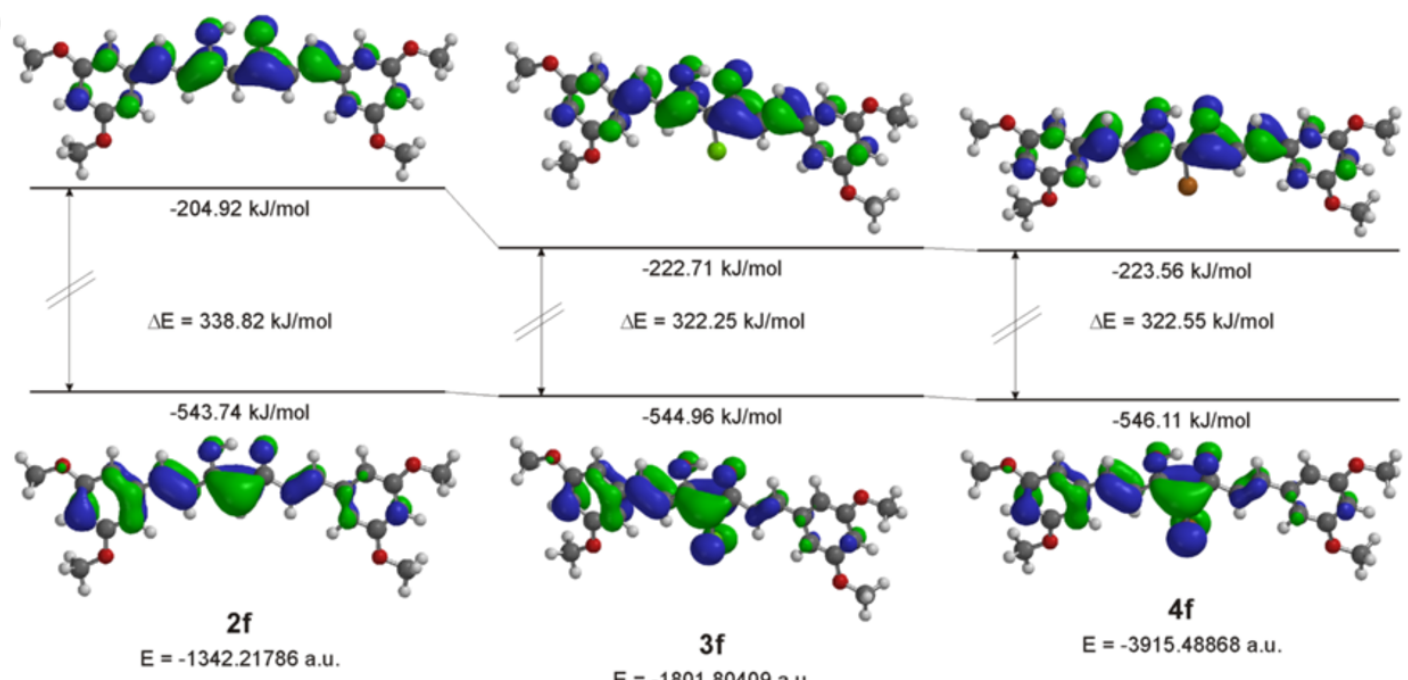

$3 f$

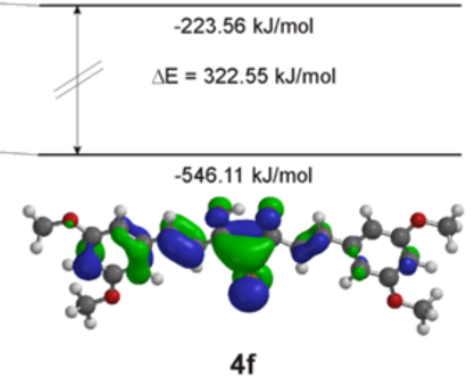

$E=-1801.80409$ a.u.

$E=-3915.48868$ a.u.

Figure 14 Molecular orbital diagram levels for HOMOs and LUMOs, computed total energies, and relative energies of compounds. (a) 2d, 3d, 4d; (b) 2e, 3e, 4e and (c) 2f, $3 f$ and $4 f$. 


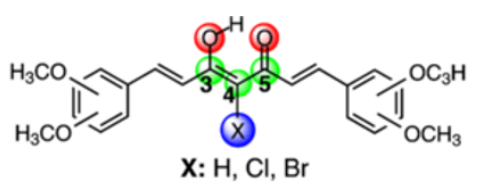

\begin{tabular}{|c|c|c|c|c|c|c|c|c|}
\hline \multicolumn{2}{|c|}{ Compound } & $\mathrm{x}$ & C3 & $\mathrm{C} 4$ & C5 & 03 & 05 & Dipole momet [debye] \\
\hline \multirow{3}{*}{ 2,6-diOCH 3} & (2d) $\mathrm{H}$ & 0.237 & 0.419 & -0.440 & 0.470 & -0.699 & -0.662 & $4.01 \mathrm{D}^{a}$ \\
\hline & (3d) $\mathrm{Cl}$ & -0.032 & 0.402 & -0.227 & 0.460 & -0.691 & -0.655 & $2.26 \mathrm{D}^{a}$ \\
\hline & (4d) $\mathrm{Br}$ & 0.028 & 0.405 & -0.297 & 0.461 & -0.690 & -0.654 & $2.12 \mathrm{D}^{a}$ \\
\hline \multirow[t]{3}{*}{ 3,4-diOCH } & (2e) $\mathrm{H}$ & 0.239 & 0.419 & -0.440 & 0.470 & -0.699 & -0.662 & $3.57 \mathrm{D}^{b}$ \\
\hline & $(3 e) C l$ & -0.026 & 0.403 & -0.229 & 0.460 & -0.692 & -0.656 & $1.88 \mathrm{D}^{b}$ \\
\hline & (4e) $\mathrm{Br}$ & 0.036 & 0.404 & -0.300 & 0.460 & -0.690 & -0.655 & $1.78 \mathrm{D}^{b}$ \\
\hline \multirow[t]{3}{*}{ 3,5- $\mathrm{diOCH}_{3}$} & (2f) $\mathrm{H}$ & 0.241 & 0.422 & -0.437 & 0.473 & -0.694 & -0.654 & $5.00 \mathrm{D}^{c}$ \\
\hline & (3f) $\mathrm{Cl}$ & -0.019 & 0.405 & -0.228 & 0.465 & -0.686 & -0.647 & $3.16 \mathrm{D}^{c}$ \\
\hline & (4f) $\mathrm{Br}$ & 0.045 & 0.407 & -0.300 & 0.466 & -0.685 & -0.646 & $3.06 \mathrm{D}^{c}$ \\
\hline
\end{tabular}

Actual dipole vector components being ${ }^{\circ} \mathrm{H}:(2.5646,-2.9206,-0.9706) ; \mathrm{Cl}:(1.5306,-1.5949,-0.4802)$; Br: $(1.4740,-1.4562,-0.4284)$. ' $\mathrm{H}$ : $(0.3729,-2.4530,-2.5646)$; Cl: $(0.2029,-1.2134,-1.4207)$; $\mathrm{Br}$ : $(0.1956,-1.1144,-1.3798)$. ${ }^{e} \mathrm{H}:(0.3458,-3.5533,-3.4903)$; Cl: (0.2967, $\left.-2.2653,-2.1816\right)$; Br: $(0.2961$, $-2.1751,-2.1264)$.

Figure 15 Natural atomic charges for the enolic structure of enolone fragment and dipole moments of $2 d-4 f$.

431.1250. EA for $\mathrm{C}_{23} \mathrm{H}_{23} \mathrm{ClO}_{6}$ : calcd $64.11 \% \mathrm{C}, 5.38 \% \mathrm{H}$; found $63.80 \% \mathrm{C}, 5.26 \% \mathrm{H}$.

\section{(1E,6E)-1,7-bis(2,5-dimethoxyphenyl)-4-chloro-1,}

\section{6-heptadiene-3,5-dione (3c)}

Yellow-orange solid, $\mathrm{mp} \quad 188.2-188.8^{\circ} \mathrm{C} .{ }^{1} \mathrm{H} \quad \mathrm{NMR}$ $\left(\mathrm{CDCl}_{3}, 500 \mathrm{MHz}\right) \delta \mathrm{ppm} 16.52(\mathrm{~s},-\mathrm{OH}), 8.09(\mathrm{~d}, 2 \mathrm{H}$, $J=15.8), 7.47(\mathrm{~d}, 2 \mathrm{H}, J=15.8), 7.16(\mathrm{~d}, 2 \mathrm{H}, J=3.0)$, $6.94(\mathrm{dd}, 2 \mathrm{H}, J=9.0, J=3.0), 6.87(\mathrm{~d}, 2 \mathrm{H}, J=9.0), 3.87$ $(\mathrm{s}, 6 \mathrm{H}), 3.83(\mathrm{~s}, 6 \mathrm{H}) .{ }^{13} \mathrm{C} \mathrm{NMR}\left(\mathrm{CDCl}_{3}, 75 \mathrm{MHz}\right) \delta$ ppm 180.5, 153.6, 153.3, 138.4, 124.7, 120.5, 117.4, $113.5,112.5,108.4,56.2$, 55.9. IR $(\mathrm{KBr}) v=1610,1579$, 1496, 1288, 1269, 1053, 1020, 974, 847, $801 \mathrm{~cm}^{-1}$. CIMS $(m / z) 433.1\left(\mathrm{MH}^{+}+2\right), 431.1\left(\mathrm{MH}^{+}\right)$. CI-HRMS for $\mathrm{C}_{23} \mathrm{H}_{24} \mathrm{ClO}_{6}^{+}$: calcd 431.1261, found 431.1262. EA for $\mathrm{C}_{23} \mathrm{H}_{23} \mathrm{ClO}_{6}$ : calcd $64.11 \% \mathrm{C}, 5.38 \% \mathrm{H}$; found $63.94 \%$ C, $5.25 \% \mathrm{H}$.

\section{(1E,6E)-1,7-bis(2,6-dimethoxyphenyl)-4-chloro-1,}

\section{6-heptadiene-3,5-dione (3d)}

Yellow-orange solid, $\mathrm{mp} \quad 159.0-160.3^{\circ} \mathrm{C} .{ }^{1} \mathrm{H}$ NMR $\left(\mathrm{CDCl}_{3}, 500 \mathrm{MHz}\right) \delta \mathrm{ppm} 16.77(\mathrm{~s},-\mathrm{OH}), 8.23$ (d, 2H, $J=16.0$ ), 7.91 (d, $2 \mathrm{H}, J=16.0), 7.28$ (dd, $2 \mathrm{H}, J=8.4, J=$ 8.4), $6.57(\mathrm{~d}, 4 \mathrm{H}, J=8.4), 3.92(\mathrm{~s}, 12 \mathrm{H}) .{ }^{13} \mathrm{C}$ NMR

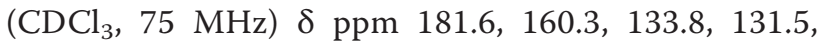
$122.8,113.2,108.5,103.7,55.9$. IR $(\mathrm{KBr}) v=1603$, 1582, 1478, 1258, 1210, 1109, 1035, $735 \mathrm{~cm}^{-1}$. CIMS $(m / z) 433.1\left(\mathrm{MH}^{+}+2\right), 431.1\left(\mathrm{MH}^{+}\right)$. CI-HRMS for $\mathrm{C}_{23} \mathrm{H}_{24} \mathrm{ClO}_{6}^{+}$: calcd 431.1261, found 431.1254. EA for $\mathrm{C}_{23} \mathrm{H}_{23} \mathrm{ClO}_{6}$ : calcd $64.11 \% \mathrm{C}, 5.38 \% \mathrm{H}$; found $64.22 \% \mathrm{C}$, $5.49 \% \mathrm{H}$.
(1E,6E)-1,7-bis(3,4-dimethoxyphenyl)-4-chloro-1, 6-heptadiene-3,5-dione (3e)

Orange solid, mp $173.8-174.6^{\circ} \mathrm{C} .{ }^{1} \mathrm{H}$ NMR $\left(\mathrm{CDCl}_{3}, 500\right.$ $\mathrm{MHz}) \delta$ ppm 16.62 (s, $-\mathrm{OH}), 7.73$ (d, 2H, $J=15.6), 7.27$ (d, $2 \mathrm{H}, J=15.6), 7.23(\mathrm{dd}, 2 \mathrm{H}, J=8.3, J=1.8), 7.14(\mathrm{~d}, 2 \mathrm{H}$, $J=1.8), 6.90(\mathrm{~d}, 2 \mathrm{H}, J=8.3), 3.96(\mathrm{~s}, 6 \mathrm{H}), 3.94(\mathrm{~s}, 6 \mathrm{H}) .{ }^{13} \mathrm{C}$ $\mathrm{NMR}\left(\mathrm{CDCl}_{3}, 75 \mathrm{MHz}\right) \delta \mathrm{ppm} 180.1,151.5,149.3,143.3$, $128.1,123.4,117.6,111.2,110.3,107.8,56.0$. IR (KBr) $v=$ 1600, 1512, 1423, 1346, 1263, 1164, 1141, 1024, 969, 804 $\mathrm{cm}^{-1}$. CIMS $(\mathrm{m} / z) 433.1\left(\mathrm{MH}^{+}+2\right), 431.1\left(\mathrm{MH}^{+}\right)$. CIHRMS for $\mathrm{C}_{23} \mathrm{H}_{24} \mathrm{ClO}_{6}^{+}$: calcd 431.1261, found 431.1270. EA for $\mathrm{C}_{23} \mathrm{H}_{23} \mathrm{ClO}_{6}$ : calcd $64.11 \% \mathrm{C}, 5.38 \% \mathrm{H}$; found $64.19 \% \mathrm{C}, 5.35 \% \mathrm{H}$.

\section{(1E,6E)-1,7-bis(3,5-dimethoxyphenyl)-4-chloro-1,}

6-heptadiene-3,5-dione (3f)

Yellow solid, mp $159.2-159.6^{\circ} \mathrm{C} .{ }^{1} \mathrm{H}$ NMR $\left(\mathrm{CDCl}_{3}, 500\right.$ $\mathrm{MHz}) \delta$ ppm 16.34 (s, $-\mathrm{OH}), 7.70(\mathrm{~d}, 2 \mathrm{H}, J=15.6), 7.37$ $(\mathrm{d}, 2 \mathrm{H}, J=15.6), 6.76(\mathrm{~d}, 4 \mathrm{H}, J=2.1), 6.53(\mathrm{dd}, 2 \mathrm{H}$, $J=2.1, J=2.1), 3.84(\mathrm{~s}, 12 \mathrm{H}) \cdot{ }^{13} \mathrm{C} \mathrm{NMR}\left(\mathrm{CDCl}_{3}, 75\right.$ $\mathrm{MHz}) \delta \mathrm{ppm} 180.1,161.1,143.5,136.8,120.2,108.4$, $106.5,102.9$, 55.5. IR $(\mathrm{KBr}) v=1624,1596,1455$, 1352, 1290, 1207, 1159, 1062, 966, $835 \mathrm{~cm}^{-1}$. CIMS $(m / z) 433.1\left(\mathrm{MH}^{+}+2\right), 431.1\left(\mathrm{MH}^{+}\right)$. CI-HRMS for $\mathrm{C}_{23} \mathrm{H}_{24} \mathrm{ClO}_{6}^{+}$: calcd 431.1261, found 431.1266. EA for $\mathrm{C}_{23} \mathrm{H}_{23} \mathrm{ClO}_{6}$ : calcd $64.11 \% \mathrm{C}, 5.38 \% \mathrm{H}$; found $63.72 \% \mathrm{C}$, $5.21 \% \mathrm{H}$.

(1E,6E)-1,7-bis(2,3-dimethoxyphenyl)-4-bromo-1, 6-heptadiene-3,5-dione (4a)

Yellow solid, mp $155.5-155.7^{\circ} \mathrm{C} .{ }^{1} \mathrm{H}$ NMR $\left(\mathrm{CDCl}_{3}, 500\right.$ $\mathrm{MHz}) \delta \mathrm{ppm} 16.86(\mathrm{~s},-\mathrm{OH}), 8.06$ (d, 2H, $J=15.8)$, 
$7.58(\mathrm{~d}, 2 \mathrm{H}, J=15.8), 7.28(\mathrm{dd}, 2 \mathrm{H}, J=8.0, J=1.0)$, $7.09(\mathrm{dd}, 2 \mathrm{H}, J=8.0, J=8.0), 6.97(\mathrm{dd}, 2 \mathrm{H}, J=8.0$, $J=1.0), 3.90(\mathrm{~s}, 6 \mathrm{H}), 3.89(\mathrm{~s}, 6 \mathrm{H}) .{ }^{13} \mathrm{C}$ NMR $\left(\mathrm{CDCl}_{3}\right.$, $75 \mathrm{MHz}) \delta \mathrm{ppm} 181.3,153.2,148.9,138.5,129.1$, 124.2, 123.1, 119.8, 114.3, 98.3, 61.4, 55.9. IR (KBr) $v=1614,1576,1482,1272,1075,1000,975,742$ $\mathrm{cm}^{-1}$. CIMS $(\mathrm{m} / z) 477.1\left(\mathrm{MH}^{+}+2\right), 475.1\left(\mathrm{MH}^{+}\right)$. CIHRMS for $\mathrm{C}_{23} \mathrm{H}_{24} \mathrm{BrO}_{6}^{+}$: calcd 475.0756, found 475.0747. EA for $\mathrm{C}_{23} \mathrm{H}_{23} \mathrm{BrO}_{6}$ : calcd $58.12 \% \mathrm{C}, 4.88 \% \mathrm{H}$; found $57.95 \% \mathrm{C}, 4.79 \% \mathrm{H}$.

\section{(1E,6E)-1,7-bis(2,4-dimethoxyphenyl)-4-bromo-1,}

\section{6-heptadiene-3,5-dione (4b)}

Brown-orange solid, $\mathrm{mp} \quad 143.1-145.6{ }^{\circ} \mathrm{C} .{ }^{1} \mathrm{H}$ NMR $\left(\mathrm{CDCl}_{3}, 300 \mathrm{MHz}\right) \delta \mathrm{ppm} 17.21(\mathrm{~s},-\mathrm{OH}), 8.01(\mathrm{~d}, 2 \mathrm{H}$, $J=15.7), 7.56(\mathrm{~d}, 2 \mathrm{H}, J=8.6), 7.48(\mathrm{~d}, 2 \mathrm{H}, J=15.7)$, $6.54(\mathrm{dd}, 2 \mathrm{H}, J=8.6, J=2.3), 6.46(\mathrm{~d}, 2 \mathrm{H}, J=2.3), 3.90$ (s, 6H), $3.86(\mathrm{~s}, 6 \mathrm{H}) .{ }^{13} \mathrm{C}$ NMR $\left(\mathrm{CDCl}_{3}, 75 \mathrm{MHz}\right) \delta$ ppm 181.5, 163.1, 160.3, 138.7, 130.7, 119.8, 117.4, 105.6, 98.4, 97.7, 55.6, 55.5. IR (KBr) $v=1595,1506$, 1464, 1298, 1277, 1252, 1212, 1030, 968, $822 \mathrm{~cm}^{-1}$. CIMS $(m / z) 477.1\left(\mathrm{MH}^{+}+2\right), 475.1\left(\mathrm{MH}^{+}\right)$. CI-HRMS for $\mathrm{C}_{23} \mathrm{H}_{24} \mathrm{BrO}_{6}^{+}$: calcd 475.0756, found 475.0776. EA for $\mathrm{C}_{23} \mathrm{H}_{23} \mathrm{BrO}_{6}$ : calcd $58.12 \% \mathrm{C}, 4.88 \% \mathrm{H}$; found $57.73 \%$ $\mathrm{C}, 4.69 \% \mathrm{H}$.

\section{(1E,6E)-1,7-bis(2,5-dimethoxyphenyl)-4-bromo-1,}

\section{6-heptadiene-3,5-dione (4c)}

Yellow solid, mp $162.9-163.4^{\circ} \mathrm{C} .{ }^{1} \mathrm{H}$ NMR $\left(\mathrm{CDCl}_{3}, 500\right.$ $\mathrm{MHz}) \delta \mathrm{ppm} 16.96(\mathrm{~s},-\mathrm{OH}), 8.06(\mathrm{~d}, 2 \mathrm{H}, J=15.8)$, $7.55(\mathrm{~d}, 2 \mathrm{H}, J=15.8), 7.15(\mathrm{~d}, 2 \mathrm{H}, J=3.0), 6.94(\mathrm{dd}, 2 \mathrm{H}$, $J=9.0, J=3.0), 6.87(\mathrm{~d}, 2 \mathrm{H}, J=9.0), 3.88(\mathrm{~s}, 6 \mathrm{H}), 3.83$ $(\mathrm{s}, 6 \mathrm{H}) .{ }^{13} \mathrm{C}$ NMR $\left(\mathrm{CDCl}_{3}, 75 \mathrm{MHz}\right) \delta \mathrm{ppm} 181.4,153.5$, $153.3,138.7,124.6,122.5,117.4,113.7,112.5,98.2$, 56.2, 55.9. IR (KBr) $v=1610,1578,1497,1289,1268,1053$, 1018, 972, $799 \mathrm{~cm}^{-1}$. CIMS $(\mathrm{m} / z) 477.1\left(\mathrm{MH}^{+}+2\right), 475.1$ $\left(\mathrm{MH}^{+}\right)$. CI-HRMS for $\mathrm{C}_{23} \mathrm{H}_{24} \mathrm{BrO}_{6}^{+}$: calcd 475.0756, found 475.0760. EA for $\mathrm{C}_{23} \mathrm{H}_{23} \mathrm{BrO}_{6}$ : calcd $58.12 \% \mathrm{C}, 4.88 \% \mathrm{H}$; found $57.90 \% \mathrm{C}, 4.80 \% \mathrm{H}$.

\section{(1E,6E)-1,7-bis(2,6 -dimethoxyphenyl)-4-bromo-1, 6-heptadiene-3,5-dione (4d)}

Yellow-orange solid, $\mathrm{mp} 126.7-127.4^{\circ} \mathrm{C} .{ }^{1} \mathrm{H}$ NMR $\left(\mathrm{CDCl}_{3}, 500 \mathrm{MHz}\right) \delta \mathrm{ppm} 17.19(\mathrm{~s},-\mathrm{OH}), 8.21(\mathrm{~d}, 2 \mathrm{H}$, $J=15.9), 8.00(\mathrm{~d}, 2 \mathrm{H}, J=15.9), 7.28(\mathrm{dd}, 2 \mathrm{H}, J=8.4$, $J=8.4), 6.57(\mathrm{~d}, 4 \mathrm{H}, J=8.4), 3.92(\mathrm{~s}, 12 \mathrm{H}) .{ }^{13} \mathrm{C}$ NMR $\left(\mathrm{CDCl}_{3}, 126 \mathrm{MHz}\right)$ enol form $\delta \mathrm{ppm} \mathrm{182.4,} \mathrm{160.3,}$ 134.1, 131.5, 124.6, 113.1, 103.7, 98.6, 55.9; diketone form $\delta \mathrm{ppm} 190.2,160.7,136.9,132.3,124.2,112.1$, 103.6, 57.5, 55.8. IR (KBr) $v=1603,1580,1477$, 1397, 1257, 1207, 1110, 1036, 737 $\mathrm{cm}^{-1}$. CIMS $(\mathrm{m} / \mathrm{z}) 477.1$ $\left(\mathrm{MH}^{+}+2\right), 475.1\left(\mathrm{MH}^{+}\right)$. CI-HRMS for $\mathrm{C}_{23} \mathrm{H}_{24} \mathrm{BrO}_{6}^{+}$: calcd 475.0756, found 475.0752. EA for $\mathrm{C}_{23} \mathrm{H}_{23} \mathrm{BrO}_{6}$ : calcd $58.12 \% \mathrm{C}, 4.88 \% \mathrm{H}$; found $58.21 \% \mathrm{C}, 4.78 \% \mathrm{H}$.
(1E,6E)-1,7-bis(3,4-dimethoxyphenyl)-4-bromo-1, 6-heptadiene-3,5-dione (4e)

Orange solid mp, $160.9-161.3^{\circ} \mathrm{C} .{ }^{1} \mathrm{H}$ NMR $\left(\mathrm{CDCl}_{3}, 500\right.$ $\mathrm{MHz}) \delta \mathrm{ppm} 17.05(\mathrm{~s},-\mathrm{OH}), 7.72(\mathrm{~d}, 2 \mathrm{H}, J=15.5)$, $7.34(\mathrm{~d}, 2 \mathrm{H}, J=15.5), 7.23(\mathrm{dd}, 2 \mathrm{H}, J=8.3, J=1.9)$, $7.13(\mathrm{~d}, 2 \mathrm{H}, J=1.9), 6.90(\mathrm{~d}, 2 \mathrm{H}, J=8.3), 3.96(\mathrm{~s}, 6 \mathrm{H})$, $3.94(\mathrm{~s}, 6 \mathrm{H}) .{ }^{13} \mathrm{C} \mathrm{NMR}\left(\mathrm{CDCl}_{3}, 75 \mathrm{MHz}\right) \delta \mathrm{ppm} 181.0$, $151.5,149.3,143.7,128.0,123.3,119.4,111.2,110.3$, 97.6, 56.0. IR (KBr) $v=1599,1512,1422,1343,1261$, 1236, 1163, 1140,1025, 967, $806 \mathrm{~cm}^{-1}$. CIMS $(\mathrm{m} / \mathrm{z})$ $477.1\left(\mathrm{MH}^{+}+2\right), \quad 475.1 \quad\left(\mathrm{MH}^{+}\right)$. CI-HRMS for $\mathrm{C}_{23} \mathrm{H}_{24} \mathrm{BrO}_{6}^{+}$: calcd 475.0756, found 475.0750. EA for $\mathrm{C}_{23} \mathrm{H}_{23} \mathrm{BrO}_{6}$ : calcd $58.12 \% \mathrm{C}, 4.88 \% \mathrm{H}$; found $58.31 \% \mathrm{C}$, $4.86 \% \mathrm{H}$.

\section{(1E,6E)-1,7-bis(3,5-dimethoxyphenyl)-4-bromo-1, 6-heptadiene-3,5-dione (4f)}

Yellow solid, mp $154.7-154.9^{\circ} \mathrm{C} .{ }^{1} \mathrm{H}$ NMR $\left(\mathrm{CDCl}_{3}, 500\right.$ MHz) $\delta$ ppm 16.79 (s, $-\mathrm{OH}), 7.68$ (d, 2H, $J=15.6$ ), $7.44(\mathrm{~d}, 2 \mathrm{H}, J=15.6), 6.76(\mathrm{~d}, 4 \mathrm{H}, J=2.2), 6.53(\mathrm{dd}, 2 \mathrm{H}$, $J=2.2, J=2.2), 3.84(\mathrm{~s}, 12 \mathrm{H}) \cdot{ }^{13} \mathrm{C} \mathrm{NMR}\left(\mathrm{CDCl}_{3}, 75\right.$

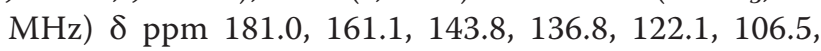
102.8, 98.1, 55.5. IR (KBr) $v=1621,1595,1461,1299$, 1209, 1157, 1063, 967, $835 \mathrm{~cm}^{-1}$. CIMS $(\mathrm{m} / z) 477.1$ $\left(\mathrm{MH}^{+}+2\right), 475.1\left(\mathrm{MH}^{+}\right)$. CI-HRMS for $\mathrm{C}_{23} \mathrm{H}_{24} \mathrm{BrO}_{6}^{+}$: calcd 475.0756, found 475.0752. EA for $\mathrm{C}_{23} \mathrm{H}_{23} \mathrm{BrO}_{6}$ : calcd $58.12 \% \mathrm{C}, 4.88 \% \mathrm{H}$; found $57.95 \% \mathrm{C}, 4.66 \% \mathrm{H}$.

\section{Additional files}

Additional file 1: Supporting file.

Additional file 2: Copies of the Spectra.

Additional file 3: deposit1.

Additional file 4: deposit2.

Additional file 5: mo4kon.

Competing interests

The authors declare that they have no competing interests.

Authors' contributions

PG all the experimental work, the spectroscopic characterization, helped to draft the manuscript; AG the single-crystal structure analysis; JK participated in the theoretical calculation; BK participated in the theoretical calculation and designed the manuscript; BŠ draft the manuscript. All the authors read and approved the final manuscript.

\section{Acknowledgements}

We are deeply indebted to Prof. Janez Plavec and Primož Šket, PhD., at the National Institute of Chemistry for solid sample NMR measurements and Dušan Žigon, PhD., at the Jožef Stefan Institute for mass spectra measurements. We also thank EN-FIST Centre of Excellence, Slovenia, for using SuperNova diffractometer. Financial support from the Ministry of Science and Technology of Slovenia and the Slovenian Research Agency is acknowledged.

Received: 8 January 2013 Accepted: 6 June 2013 Published: 25 June 2013 


\section{References}

1. Aggarwal BB, Sundaram C, Malani N, Ichikawa H: Curcumin: the Indian solid gold. Adv Exp Med Biol 2007, 595:1-75.

2. Srimal RC, Dhawan BN: Pharmacology of Diferuloyl Methane (Curcumin), a Non-Steroidal Anti-Inflammatory Agent. J Pharm Pharmacol 1973, 25:447-452.

3. Sharma OP: Antioxidant Activity of Curcumin and Related Compounds. Biochem Pharmacol 1976, 25:1811-1812.

4. Singh S, Aggarwal BB: Activation of Transcription Factor NF-KB is Suppressed by Curcumin (Diferulolylmethane). J Biol Chem 1995 270:24995-25000.

5. Goel A, Kannumakkara AB, Aggarwal BB: Curcumin as "Curecumin": From Kitchen to Clinic. Biochem Pharmacol 2008, 75:787-809.

6. Lantz RC, Chen GJ, Solyom AM, Jolad SD, Timmermann BN: The Effect of Turmeric Extracts on Inflammatory Mediator Production. Phytomed 2005, 12:445-452.

7. Yang F, Lim GP, Begum AN, Ubeda OJ, Simmons MR, Ambegaokar SS, Chen P, Kayed R, Glabe CG, Frautschy SA, Cole GM: Curcumin Inhibits Formation of Amyloid $\beta$ Oligomers and Fibrils, Binds Plaques, and Reduces Amyloid in Vivo. J Biol Chem 2005, 280:5892-5901.

8. Ryu EK, Choe YS, Lee K-H, Choi Y, Kim B-T: Curcumin and Dehydrozingerone Derivatives: Synthesis, Radiolabeling, and Evaluation for $\beta$-Amyloid Plaque Imaging. J Med Chem 2006, 49:6111-6119.

9. Leu T-H, Maa M-C: The Molecular Mechanisms for the Antitumorigenic Effect of Curcumin. Curr Med Chem-Anti-Cancer Agents 2002, 2:357-370.

10. Moos PJ, Edes K, Mullally JE, Fitzpatrick FA: Curcumin Impairs Tumor Suppressor p53 Function in Colon Cancer Cells. Carcinog 2004, 25:1611-1617.

11. Fujisawa S, Atsumi T, Ishihara M, Kadoma Y: Cytotoxicity, ROS-Generation Activity and Radical-Scavenging Activity of Curcumin and Related Compounds. Anticancer Res 2004, 24:563-569.

12. Aggarwal BB, Kumar A, Bharti AC: Anticancer Potential of Curcumin: Preclinical and Clinical Studies. Anticancer Res 2003, 23:363-398.

13. Tønnesen HH, Karlsen J, Mostad A: Structural Studies of Curcuminoids I. The Crystal Structure of Curcumin. Acta Chem Scand B 1982, 36:475-479.

14. Parimita SP, Ramshankar YV, Suresh S, Row TNG: Redetermination of Curcumin: (1E,4Z,6E)-5-Hydroxy-1,7-Bis(4-Hydroxy-3-Methoxyphenyl) hepta-1,4,6-Trien-3-One. Acta Cryst. E 2007, 63:0860-0862.

15. Mague JT, Alworth WL, Payton FL: Curcumin and Derivatives. Acta Cryst. C 2004, 60:0608-0610.

16. Sanphui P, Goud NR, Khandavilli UBR, Bhanoth S, Nangia A: New polymorphs of curcumin. Chem Commun 2011, 47:5013-5015.

17. Balasubramanian K: Molecular Orbital Basis for Yellow Curry Spice Curcumin's Prevention of Alzheimer's Disease. J Agric Food Chem 2006, 54:3512-3520.

18. Cornago P, Claramunt RM, Bouissane L, Alkorta I, Elguero J: A Study of the Tautomerism of $\beta$-Dicarbonyl Compounds with Special Emphasis on Curcuminoids. Tetrahedron 2008, 64:8089-8094.

19. Payton F, Sandusky P, Alworth WL: NMR Study of the Solution Structure of Curcumin. J Nat Prod 2007, 70:143-146.

20. Nardo L, Andreoni A, Tønnesen HH: Intramolecular H-Bond Formation Mediated De-Excitation of Curcuminoids: a Time-Resolved Fluorescence Study, In Hydrogen Bonding and Transfer in the Excited State. Volume I\&ll.; 2011:353-375.

21. Nardo L, Andreoni A, Masson M, Haukvik T, Tønnesen HH: Studies on Curcumin and Curcuminoids. XXXIX. Photophysical Properties of Bisdemethoxycurcumin. J Fluoresc 2011, 21:627-635.

22. Nardo L, Andreoni A, Bondani M, Masson M, Haukvik T, Tønnesen HH: Studies on Curcumin and Curcuminoids. XLVI. Photophysical Properties of Dimethoxycurcumin and Bis-dehydroxycurcumin. J Fluoresc 2012, 22:597-608

23. Agrawal DK, Mishra PK: Curcumin and Its Analogues: Potential AnticancerAgents. Med Res Rev 2010, 30:818-860.

24. Pedersen U, Rasmussen PB, Lawesson S-O: Synthesis of Naturally Occurring Curcuminoids and Related Compounds. Liebigs Ann. Chem 1985, 8:1557-1569.

25. Shen L, Ji H-F: Theoretical Study on Physicochemical Properties of Curcumin. Spectrochim. Acta, Part A 2007, 67:619-623.

26. Ghosh R, Mondal JA, Palit DK: Ultrafast Dynamics of the Excited States of Curcumin in Solution. J Phys Chem B 2010, 114:12129-12143.
27. Neumann CS, Fujimori DG, Walsh CT: Halogenation Strategies in Natural Product Biosynthesis. Chem Biol 2008, 15:99-109.

28. Jamode VS, Babrekar SA: Synthesis of Propan-1,3-Diones and Chromens. Asian J Chem 2009, 21:3553-3556.

29. Lee K-H, Lin L, Shih CC-Y, Su C-Y, Ishida J, Ohtsu H, Wang H-K, Itokawa H, Chang C: Novel Curcumin Analogues and uses thereof. WO 2006, 2006044379(A2)

30. Lin L, Shi Q, Nyarko AK, Bastow KF, Wu C-C, Su C-Y, Shih CC-Y, Lee K-H: Antitumor Agents. 250. Design and Synthesis of New Curcumin Analogues as Potential Anti-Prostate Cancer Agents. J Med Chem 2006, 49:3963-3972

31. Lin L, Shi Q, Su C-Y, Shih CC-Y, Lee K-H: Antitumor Agents 247. New 4-Ethoxycarbonylethyl Curcumin Analogs as Potential Antiandrogenic Agents. Bioorg Med Chem 2006, 14:2527-2534.

32. For a monograph, see De Kimpe N, Verhé R: The Chemistry of a-Haloketones, a-Haloaldehydes, and a-Haloimines. New York: Wiley; 1988.

33. Larock RC: Comprehensive Organic Transformation. 2nd edition. New York: VCH Publishers Inc; 1999:717-718.

34. Khan AT, Ali MA, Goswami P, Choudhury LH: A Mild and Regioselective Method for $\alpha$-Bromination of $\beta$-Keto Esters and 1,3-Diketones Using Bromodimethylsulfonium Bromide (BDMS). J Org Chem 2006, 71:8961-8963

35. Pravst I, Zupan M, Stavber S: Solvent-Free Bromination of 1,3-Diketones and $\beta$-Keto Esters with NBS. Green Chem 2006, 8:1001-1005.

36. Alinezhad H, Tajbakhsh M, Tehrani SS: Selective Monobromination of 1,3-Diones with $\mathrm{N}$-Bromosaccharin/ $\mathrm{Mg}\left(\mathrm{ClO}_{4}\right)_{2}$ System in Solution and under Solvent-Free Conditions. Bull. Korean Chem Soc 2011, 32:1543-1546.

37. Galer P, Kosmrlj B, Sket B: Highly Regioselective Halogenation of 1-Phenyl-3-(3,5-Dimethoxyphenyl)-Propane-1,3-Dione. Tetrahedron 2011, 67:2103-2109

38. Weber WM, Hunsaker LA, Abcouwer SF, Deck LM, Jagt DLV: Anti-Oxidant Activities of Curcumin and Related Enones. Bioorg Med Chem 2005, 13:3811-3820

39. Takahashi T, Hijikuro I, Sugimoto H, Kihara T, Shimmyo Y, Niidome T: Novel Curcumin Derivative. WO 2008, 2008066151(A1).

40. Amolins MW, Peterson LB, Blagg BSJ: Synthesis and Evaluation of Electron-Rich Curcumin Analogues. Bioorg Med Chem 2009, 17:360-367.

41. Nurfina AN, Reksohadiprodjo MS, Timmerman H, Jenie UA, Sugiyanto D, van der Goot H: Synthesis of some Symmetrical Curcumin Derivatives and their Antiinflammatory Activity. Eur J Med Chem 1997, 32:321-328.

42. Hahm E-R, Cheon G, Lee J, Kim B, Park C, Yang C-H: New and Known Symmetrical Curcumin Derivatives Inhibit the Formation of Fos-Jun-DNA Complex. Cancer Lett 2002, 184:89-96.

43. Gilli G, Gilli P: The Nature of the Hydrogen Bond. Outline of a Comprehensive Hydrogen Bond Theory. Oxford: Oxford University Press; 2009.

44. Perrin CL: Symmetry of Hydrogen Bonds in Solution. Pure Appl Chem 2009, 81:571-583.

45. Perrin CL: Are Short, Low-Barrier Hydrogen Bonds Unusually Strong? Acc Chem Res 2010, 43:1550-1557.

doi:10.1186/1752-153X-7-107

Cite this article as: Galer et al: Structures in solid state and solution of dimethoxy curcuminoids: regioselective bromination and chlorination. Chemistry Central Journal 2013 7:107.

\section{Publish with ChemistryCentral and every scientist can read your work free of charge \\ "Open access provides opportunities to our colleagues in other parts of the globe, by allowing anyone to view the content free of charge." \\ W. Jeffery Hurst, The Hershey Company.}

- available free of charge to the entire scientific community

- peer reviewed and published immediately upon acceptance

- cited in PubMed and archived on PubMed Central

- yours - you keep the copyright

Submit your manuscript here:

http://www.chemistrycentral.com/manuscript/<smiles>c1ccccc1</smiles>

ChemistryCentral 